\title{
La escritura humanística en la Europa del Renacimiento
}

\author{
Juan Carlos Galende Díaz*
}

\begin{abstract}
RESUMEN
Uno de los méritos más relevantes de

la «escritura humanística» es el haberse impuesto en Europa como

escritura virtualmente única $y$, posteriormente, haberse extendido por el resto de los continentes, siendo en

América escritura sin rival -dato de sumo interés desde el punto de vista gráfico y cultural-. Pero existen otros motivos que justifican su estudio, como son: a) el hecho de que dicha letra sea la base y origen de la escritura contemporánea, tanto manuscrita como impresa; b) su importancia gráfico-cultural para entender el Renacimiento; c) con relación al proceso gráfico y evolución de la escritura latina, la letra renacentista constituye el retorno a las formas antiguas de los modelos carolinos; d) su introducción coincide con importantes cambios ideológicos $y$

socio-culturales; y e) su difusión y promoción inicial depende más de la

\section{ABSTRACT}

One of the most relevant merits of the "humanistic writing" is the fact that it was imposed in Europe as virtualy the only one writing style and, later on, its extension to the rest of the world. The fact that in America had no rivals is interesting under the graphic and cultural point of view. But there are other following reasons to justify its study: a) the fact that this writing is the origin and base of the modern writing, both handwritten and printed; b) its graphic and cultural importance to understand the Renaissance; c) with relation to the graphic process and the evolution of the latin writing, the Renaissance style of writing constitutes the return to the ancient ways of the Carolingian models; d) its introduction coincides with important ideologic and socio-cultural changes; and e) its initial promotion and difussion depends most importantly on the decission of a restricted number of
\end{abstract}

* UCM. 
voluntaria decisión de un restringido número de centros y hombres cultos:

los humanistas y los profesionales, v. gr. escribanos, notarios, profesores,

etc. -cuyos nombres nos son histórica y documentalmente conocidos- que de la masa popular. La estructuración del presente artículo es sencilla y pretende ser clara, con

los siguientes apartados: 1) breve introducción exponiendo las peculiaridades de carácter general relativas a la letra humanística;

2) panorámica histórico-cultural del período renacentista; 3) nombres con

que se ha designado a esta letra; 4) origen y desarrollo de esta escritura con indicación de sus principales promotores, escuelas y círculos de intelectuales; 5) etapas básicas de su evolución; y 6) tipos de letra humanística y características de cada uno de ellos. Por último, además de una bibliografía básica, dividiéndola

por temas, en orden a ilustrar los distintos aspectos tratados, se presentan una serie de reproducciones gráficas con textos en letra humanistica. institutions and cultivated men: the humanists and a group of professionals like clerks, notaries, professors, etc., both historic and documentary known, and less on the mass.

The structure of this article is simple and tries to be clear, containing the following chapters: 1) a brief introduction about the general characteristics of the humanistic writing; 2) the historic and cultural situation of the Renaissance; 3) the different definitions of this type of writing; 4) origin and development of this writing, with the mention of its principal supporters, schools and intellectual groups; 5) its evolution basic steps; and 6) types and characteristics of the humanistic writing. Finally, there is a basic bibliography divided in subjects in order to enlighten the different aspects studied, and a series of graphic reproductions texts in humanistic writing.

\section{INTRODUCCIÓN}

A diferencia de escrituras anteriores, la «humanística» se ha caracterizado por haberse impuesto en Europa como virtualmente única y, más tarde, haberse extendido por el resto de los continentes, siendo en América escritura sin rival ${ }^{1}$.

Sobre aspectos generales referentes a la "escritura humanística» pueden consultarse las siguientes obras: Ecrire a la fin du Moyen-Age. Le Pouvoir et l'Ecriture en Espagne et en Italie (1450-1530), Marsella, 1990; F. GasparRI, «Enseignements et techniques de l'écriture du Moyen Age à la fin du xvı siécle", "Scrittura e Civiltà", 7 (1983), pp. 201-224; Humanistic Script of the Fifteenth and Sixteenth and Sixteenth Centuriers, Oxford, 1960; V. M. MALOV, Les Origines de l'Ecriture moderne: Paléographie des Documents Français de la fin du xve au xville Siécle. Moscú, 
Además del interés que tiene para entender el Renacimiento, no hay que olvidar que la letra "humanística" es la base y origen de la escritura contemporánea y, con relación al proceso gráfico y evolución de la escritura latina, que la letra renacentista, en palabras de Giorgio Cencetti ${ }^{2}$, es la "vuelta pura y simple a formas antiguas", advirtiendo que su introducción se debe más que a la masa popular, a la voluntaria decisión de un restringido número de centros y personas: las universidades, cancillerías y notarías con sus oficiales y maestros, y los humanistas, cuyos nombres nos son histórica y documentalmente conocidos. Asimismo, hay que resaltar, como manifiesta el autor citado, que mientras en todos los cambios escriturarios precedentes "las tendencias gráficas internas" fueron elemento decisivo, en la aparición de la escritura "humanística" el componente determinante procede de tres factores, a cual más importante: las corrientes culturales (mentes renacentistas, alejadas de la cancillería), las tendencias gráficas y la profesionalidad de los escribanos oficiales.

A mi entender, el origen e implantación de la letra "humanistica" se debe tanto al impulso voluntario de expertos en las técnicas escriptorias como a numerosas personas extrañas al ejercicio profesional, pero no por eso ajenas al aprendizaje y práctica constante de la lectura, en parte deslumbradas por la magia del arte y formas gráficas del lenguaje escrito, pero, sobre todo, por lo que la nueva escritura representaba desde el punto de vista ideológico y cultural. Es evidente que las transformaciones de la escritura son expresiones de mutaciones de la mentalidad o del carácter; la historia de la escritura, considerada ésta como una actitud privativa del hombre, viene condicionada por las coordenadas culturales de cada situación histórica ${ }^{3}$.

Pienso, en consecuencia, que el aspecto paleográfico no se puede desligar del caudal de otros hechos culturales y sociales y del fenómeno de la "alfabetización", que transforma aquél en un "hecho cultural". No se puede olvidar que el "Humanismo" fue quien "hizo entrar los estudios de las doctrinas crítico-documentales por caminos que necesariamente habrían de desembocar en su etapa científica", como dice textualmente el prof. Floriano Cumbreño ${ }^{4}$. No podemos ignorar tampoco que «el período

1975; B. L. ULLMAN, The origin and development of humanistic script, Roma, 1960; y J. WARDROP, The Script of Humanism. Some Aspects of Humanism Script, Oxtord, 1963.

2 G. CenCETTI, Compendio di Paleografia Latina, Roma, 1978, p. 79.

3 C. Álvarez MÁRQUEz, Escritura latina en la Edad Moderna: la escritura humanística, Sevilla, 1995, p. 3.

4 A. C. Floniano Cumbreño, Curso General de Paleografía y Paleografía y Diplomática Españolas, Oviedo, 1946, p. 30. 
que se conoce con el nombre de Renacimiento se presenta a nuestros ojos con una gran variedad de matices, de sentidos $y$ de tonos. Humanistas moderados y radicales, corriente cristiana y corriente pagana - paganizante, excesos lamentables y reacciones exageradas constituyen un cuadro algo confuso, ante el cual una crítica escrupulosa puede vacilar antes de lanzar sus fallos. $Y$ es que el Renacimiento no fue un sistema sino un espíritu, no una doctrina coherente sino un principio: la exaltación del hombre ${ }^{5}$, y también la revalorización de la cultura.

El Renacimiento y el "Humanismo", movimiento y fenómeno intelectual típicamente renacentista, supusieron desde el siglo $x v$ un viraje radical en la trayectoria histórica y conceptual del mundo occidental. Con este cambio brusco, fruto de numerosos factores, pero especialmente de la evolución progresiva de la sociedad y con repercusiones en el campo intelectual, político, económico y religioso, se inaugura una nueva etapa histórica y con ella el nacimiento de las escrituras modernas.

\section{PANORÁMICA HISTÓRICO-CULTURAL DEL RENACIMIENTO}

Como acabo de exponer, el "Renacimiento" y el "humanismo renacentista" - fenómeno complejo de orígen poligenético- en cuanto representante del aspecto intelectual de aquél, no pueden considerarse como simples hechos aislados surgidos de repente en una época y lugar determinado cuyo nacimiento haya que atribuirlo al acaso o como producto simplista de una sola fuente e iniciativa. Se trata de un período temporal con delimitaciones bastante precisas (siglos XIV-XVI) en el que, a causa de una serie de factores de distinta naturaleza, si se quiere coyunturales, pero indudablemente de orden social, ideológico y cultural, la sociedad occidental, comenzando por Italia, experimentará profundas transformaciones de tipo económico-social, político, religioso, artístico y aun personal, circunstancias éstas que necesariamente conducirán a nuevas mentalidades, nuevos gustos y valoración distinta aun de los principios y verdades considerados hasta entonces, si no como absolutos e inventables, al menos como trascendentales y básicos ${ }^{6}$.

A. F. ARNolD, Cultura del Renacimiento, 3. ${ }^{3}$ ed., Barcelona, 1936, pp. 4-7.

- Entre la producción bibliográfica de carácter histórico-cultural referente a este período destacan, entre otros, los estudios que se exponen a continuación: M. BAtLlori, Humanismo y Renacimiento. Estudios hispano-europeos, Barcelona, 1987; H. BUSCH y B. LOHSE, El Renacimiento, Madrid, 1966; A. ChASTEL, L'Europe de le Renaissance, Bruselas, 1963; J. DelumeAu, La civilizacion del Renacimiento, Barcelona, 1977; J. Dresdeu, Humanismo y Renacimiento, Madrid, 
El hombre occidental, arrastrado por su prurito de autosuficiencia, empezó a contemplar con espíritu crítico no sólo las dos instituciones que habían ejercido el control de un cuerpo y alma durante la Edad Media: el feudalismo y la Iglesia, sino también a sus autoridades y representantes más genuinos. Con el auge de las ciudades, a partir del siglo $\mathrm{XI}$, el incremento del tráfico por tierras y mares y la instauración de las monarquías absolutas en los siglos $\mathrm{XV}$ y $\mathrm{xVI}$, se derrumbó ineludiblemente el feudalismo político y también el económico. Los nobles, ante su catástrofe económica, hubieron de ceder grandes porciones de sus tierras, bienes y derechos a los burgueses. Incluso la manera feudal de hacer la guerra resultaba ya inoperante. Por todo ello, la única alternativa de supervivencia para estos aristócratas era la de brindar su apoyo al rey y convertirse en cortesanos y aduladores, siendo una de las clases más criticadas y satirizadas en la literatura renacentista.

Abierto por las cruzadas el camino del intercambio comercial en el Próximo Oriente y abandonado, en buena medida, el pillaje y la piratería por los nórdicos: las vías de comunicación quedan despejadas a través de Europa y el Mediterráneo, se expande el comercio, la industria cobra nuevos bríos, florecen las ciudades situadas en las rutas de tráfico y se configura el modelo demográfico del futuro. Las ciudades fundadas sobre la base de una economía no agrícola, sino urbana y monetaria, sirven de apoyo a las ricas y variadas empresas artísticas y literarias del período humanístico.

Dado que el Renacimiento entraña en sí y señala la idea del desenvolvimiento del Estado Nacional y de su compañero el "nacionalismo", la historia política de este período se convierte inevitablemente en un relato de expansiones, equilibrios de fuerza y guerras fluctuantes. Las grandes guerras de los siglos XV-XVI perseguían objetos sociales más que políticos, y muchas de las luchas tuvieron una finalidad puramente religiosa, como apunta el historiador italiano Delio Cantimori ?

Renacimiento, Valencia, 1970: E. Garcia Estébanez, El Renacimiento: E GARIN, La revolución cultural del Renacimiento, humanismo y sociedad, Madrid, 1987; E. Genaissance, París, 1986; J. I. GutiérRez NIETO, EI Barcelona, 1981; E. GILSON, Humanisme el Rerno, Barcelona, 1975; J. R. HALE, The civilization of Renacimiento y los origenes del mundo moder. HaY, La época del Renacimiento: el amanecer de Europe in the Renaissance, New York, 1995 , D. HaY, Lacentista y mundo clásico, Madrid, 1992; $\mathrm{S}$. la Edad Moderna, Barcelona, 1969; Humanid, 1984; Ch. G. NAUERT, Humanism and the culture of MASON, Historia de las ciencias, Madrid, M. A. PEREZ SAMPER, Las claves de la Europa renacentista, 1453-1556, Barcelona, 1991.

7 D. CANTIMORI, Humanismo y religiones en el Renacimiento, Barcelona, 1984. 
En una época en que los valores clásicos y las propias autoridades intelectuales ganaban constantemente terreno, es natural que se viesen expuestas a la crítica no sólo el poder temporal sino también el espiritual eclesiástico. El clasicismo era un culto en si mismo. El incremento del nacionalismo, característico del Renacimiento, contribuye decididamente al auge de la Reforma.

Entre todas la Bellas Artes, acaso sea la "arquitectura» la que mejor demuestra hasta qué punto el Renacimiento fue un resurgir de la antigüedad. Los espíritus selectos del "humanismo", consagrados con fervor al estudio e imitación de la antigüedad griega y romana, se enamoran de la simplicidad antigua, determinando una reacción general de las artes en el sentido de las formas simples con que se inaugura el Renacimiento, y en la augusta nobleza de las ruinas del solar clásico descubren los arquitectos la belleza de los órdenes antiguos que quieren introducir en sus nuevas creaciones ${ }^{8}$.

Como surgiendo de entre las últimas filigranas artísticas medievales, la "escultura" europea del Renacimiento presenta la unión de dos tendencias esencialmente opuestas, pero que en lo externo se complementan: el concepto sentimental y romántico producido por las creencias y poesías de la Edad Media, y las formas acabadas, blandas y humanas, inspiradas en la antigüedad clásica. Ambas tendencias, todavía embrionarias a fines del siglo XIII, fueron desarrollándose en las centurias siguientes, especialmente en el XVI.

Quizás, uno de los factores más importantes de este gran resurgimiento lo constituya la "pintura», destacando, por encima de las demás, las escuelas italianas y flamencas ${ }^{9}$.

La concepción del Renacimiento como un súbito salto hacia adelante parece recibir ulterior corroboración en el campo de la "música». La invención de la imprenta propició la difusión de la música. En el Renacimiento aparecen nuevos géneros musicales como el coral, el oratorio y la ópera ${ }^{10}$.

En «literatura", por Renacimiento se entiende el resurgimiento del cultivo de las letras clásicas grecolatinas, ciertamente en cuanto a su forma

8 Nociones e ideas tomadas de las obras: L. BENÉvOLO, Historia de la arquitectura del Renacimiento, 2 vols., Madrid, 1973; y P. MURRAY, Arquitectura del Renacimiento, Madrid, 1979.

9 Estas y otras materias de naturaleza artística son tratadas en profundidad en la obra clásica: E. PANOFSKY, Renacimiento y renacimiento en el arte occidental, Madrid, 1975.

10 Noticias referentes a este tema pueden consultarse en el estudio: G. REESE, Music in the Renaissance, New York, 1959. 
externa de lenguaje y estilo, pero sobre todo, en lo relativo a su ideología y espíritu laico. De aquí arranca la distinción entre letras humanas y divinas.

El Renacimiento, al apartarse de las ideas dominantes de la Edad Media tratando de sustituirlas por una concepción más "humana" del mundo, resucitó la afición al estudio de las literaturas clásicas -griega y romana-, presentando la vida de aquellos puebios como un tipo ideal de humanidad en sus aspectos literario, político y social ${ }^{11}$.

La renovación de estudios filosóficos, con los que se inaugura la Edad Moderna de la "filosofía" y se concluye la "filosofía medieval», tiene lugar durante la segunda mitad del siglo xV y a lo largo de todo el XVI. Es un período revestido de la idiosincrasia típica de las épocas de transición; en el seno de las escuelas que aparecen durante el Renacimiento se adivinan los caracteres de la filosofía moderna al lado de ideas que se conservan de la época escolástica. En opinión de la historiadora Celia Colombo -que comparto-, el "Humanismo» dió nueva vida a la antigüedad clásica, puso los cimientos de la civilización moderna y el estudio del hombre llega a ser principio esencial del "Humanismo" ${ }^{12}$.

Tanto los viajes de exploración como los culturales cuentan entre los más insoslayables fenómenos del Renacimiento. Una verdadera fiebre exploradora se apodera de los navegantes, alentada por inventos tan decisivos como la brújula y el astrolabio, y lo mismo ocurre entre estudiosos e intelectuales ${ }^{13}$.

El aumento del conocimiento humano originado por las cruzadas, el desenvolvimiento de las ciudades, la elevación social del elemento secular y las escuelas árabes, se convierten en las causas principales que contribuyen eficazmente a despertar el espíritu científico de la Baja Edad Media. Los grandes esfuerzos del "humanismo" realizados gracias a espíritus inquietos empeñados en reanudar la interrumpida cadena de tradiciones intelectuales y morales de la antigüedad clásica, trajo consigo una revolución intelectual que no podia dejar de ejercer peculiar influencia sobre el mencionado espíritu renovador y científico de la última etapa del periodo medieval, llamado a impulsar progresivamente las ciencias físico-naturales y las ciencias matemáticas del período renacentista.

\footnotetext{
Destaca, por su contenido relativo al tema, el trabajo de investigación: R. CLEMENTS, Pieta poesis: literary and humanistic theory in Renaissance, Roma, 1960.

12 C. Colombo, Humanismo y Renacimiento, Madrid, 1984.

13 Sobre este asunto, se considera clásica la obra: B. PENROSE, Travel and discovery in the Renaissance, 1420-1620, Philadelphia, 1952.
} 
Por todo ello, el Renacimiento, para innumerables historiadores y cultivadores de la cultura, representa la esplendida aurora de la gran revolución artística y científica que abre a la ciencia los senderos de la observación de la naturaleza y de la experimentación que habian de afianzarla sobre más sólidos cimientos.

La historiadora María de los Angeles Pérez Samper, tras señalar como principales características del Renacimiento las de tipo socio-cultural, considera que éstas constituyen el punto de separación y, a la vez, el de enlace entre las Edades Media y Moderna, perpetuadas en épocas posteriores bajo distintas facetas: nacionalismo, frente al universalismo religioso; urbanismo comercial, frente al regionalismo rural y agrícola; autoridad centrífuga feudal, frente a la autoridad democrática centrípeta; el individuo, frente a la colectividad; el más "aca», frente al más "allá»; $y$, finalmente, la ciencia y nuevas corrientes ideológicas, frente a tradición y superstición ${ }^{14}$.

En el plano histórico, cabe señalar algunos hechos importantes acaecidos en el siglo xv que, sin duda, contribuyeron a marcar la decisiva ruptura con el pasado y a posibilitar, desde distintos puntos de vista, la apertura a una renovada concepción de la vida: la llegada al pontificado de Martín $V$ y Nicolás $V$, la caída de Constantinopla, la invención de la imprenta, la plena floración de las Universidades, la incorporación de la nobleza y de los laicos a la cultura del libro, y los grandes descubrimientos científicos. De esta forma, se da paso al Renacimiento, primero en Italia, transfiriéndose después, al resto de Europa.

No faltan autores, como el doctor Fernández Catón, que abogan y proponen como hecho fundamental y factor determinante de la renovación renacentista y la nueva concepción de la vida, de la política, de la religión y de la cultura, la llegada al pontificado de los papas Martín V y Nicolás V; el primero elegido pontífice en 1417 -en el concilio de Constanza-y el segundo en 1447. Ambos deseosos de consolidar y armonizar las nuevas ideas y movimientos reformistas con la concepción cristiana surgida en torno a la Iglesia - ya en el siglo xIV - y de afianzar mediante nuevos rumbos los problemas internos de la Iglesia y las relaciones amistosas con el Imperio Bizantino.

Probablemente fue Tomaso Parentucelli -Nicolás $\mathrm{V}$, al ser elevado al papado (1447-1455) - quien abrió de par en par las puertas a las corrientes renovadoras, tímidamente aceptadas por su antecesor en el solio pontificio. De ahí que se le llame "el papa humanista" por antonomasia, pues

14 M. A. Pérez Samper, Las claves de la Europa renacentista, 1453-1556, Barcelona, 1991. 
a él se debe el decidido y firme apoyo prestado a los grandes humanistas de su época, tanto italianos como extranjeros, porque siendo el "Humanismo" el cultivo de la cultura clásica greco-latina, quiso rodearse de las figuras más eminentes de este movimiento y que más influyeron en su difusión por Europa. Muy pronto convierte la corte de Roma y, con el mecenazgo de los Médicis, también la de Florencia, en los dos grandes focos de irradiación europea de la nueva cultura humanista. Nicolás $V$, por su condición de auténtico humanista y gran bibliófilo, fue el creador de la Biblioteca Vaticana al aportar, como primer fondo, los códices y manuscritos adquiridos a lo largo de su vida y los primeros incunables impresos en Italia y fuera de ella ${ }^{15}$.

Otro hecho determinante e influyente, con repercusiones en el Renacimiento, fue la caída de Constantinopla (la "Roma del Oriente") en 1453, capital del imperio bizantino, con consecuencias de orden político y cultural no sólo para Bizancio sino para toda Europa. Con este acontecimiento se cierra definitivamente el Medievo y se abre una nueva etapa para toda la humanidad.

En este mismo siglo tiene lugar un importante hito histórico relacionado con la cultura del libro: la invención de la imprenta. El «Humanismo" encontraba en el nuevo "Ars impressoria» el mejor vehículo para difundir sus postulados y sus obras. Con el nacimiento de la imprenta, se acrecienta en las clases superiores el deseo y afán de coleccionar los primeros libros salidos al mercado, expresión de nuevos valores culturales y, a su vez, fuente y origen del surgimiento de numerosas bibliotecas públicas y particulares, algunas de gran relieve y alto significado ${ }^{16}$.

A medida que transcurre el siglo xv se observa otro fenómeno de suma importancia: la lenta pero constante incorporación de la nobleza y de los laicos a la cultura del libro y a su posesión, hasta entonces reservada a los monjes, clérigos y estudiantes de las escuelas monásticas y catedralicias, y estudios episcopales y universitarios. Con ello se abría un nuevo mercado al libro impreso, que los impresores, los artesanos y los mercaderes del libro supieron fomentar y aprovechar. Así nace en Europa el interés por la adquisición, lectura, estudio y conocimiento de las obras de autores griegos y romanos, e igualmente por los escritos de los representantes y

15 J. M. Feanández Catón, «Prólogo", Creadores del libro. Del Medievo al Renacimiento, Madrid, 1994, pp. XXII-XXIV.

16 Cuestión que ya he tratado en un estudio anterior: J. C. GALENDE, "Las bibliotecas de los humanistas y el Renacimiento", Revista General de Información y Documentación, 6/2 (1996), pp. 91-123. 
especialistas de la antigüedad cristiana. El prestigio de las Universidades y de sus maestros, los movimientos ideológicos surgidos en ellas y el cada día más frecuente uso de obras que, hasta mediados del siglo $x \mathrm{~V}$, o no se conocían o eran de difícil adquisición y lectura, aportarán la savia más rica y pujante hacia una decisiva transformación de la mentalidad de la sociedad medieval ${ }^{17}$.

Al lado del "humanismo" cultural acaecen, durante los siglos XIV, XV y principios del XVI, los grandes descubrimientos científicos que van a contribuir decisivamente al enriquecimiento de la ciencia, la cultura y el progreso de la humanidad.

Este proceso histórico de la cultura y del pensamiento en Europa, a lo largo del Medievo, pasando por el "Humanismo" y desembocando en el Renacimiento, tiene su mejor manifestación en el códice manuscrito y en el libro impreso e ilustrado. La cultura literaria del Renacimiento, en palabras del profesor Fontán, se caracteriza, junto con la invención tecnológica de la imprenta, por la confluencia de tres elementos principales: la restauración del latín de los antiguos (clásico y tardío) como lengua literaria y lengua de comunicación internacional y de cultura, la recuperación de los autores clásicos greco-romanos y la reanudación del estudio del griego en los países occidentales de Europa ${ }^{18}$.

Para el mundo renacentista nada mejor que una escritura elegante, nítida y armoniosa -reflejo y plasmación del pasado clásico y principal vehículo transmisor de la ciencia, de la cultura y de la ley- podría representar el "nuevo espíritu» y la "nueva sociedad", nacidos al socaire de múltiples circunstancias, factores y tendencias, pero, sobre todo, símbolo de un amplio movimiento renovador y del ansiado deseo de transformación y de cambio ${ }^{19}$.

Al “Humanismo» - según Jole Mazolenni- se debe no sólo el reflorecer de los estudios clásicos y el resurgir literario y cultural —el interés por la creación de ricas bibliotecas-, sino también la transformación de los caracteres externos de la escritura, cuya expresión gráfica, de una parte, continúa - aunque modificándola - el tipo gótico y, de otra, coloca junto a éste un alfabeto nuevo, calco y reproducción modificada y perfeccionada

J. M. Fernández Catón, op. cit., pp. XXIV-XXVII.

18 A. FonTÁ, "Humanismo, Renacimiento y letras", Creadores del libro. Del Medievo al Renacimiento, p.163.

19 Véanse los estudios: A. Petrucci, Libri, Scrittura e Publico nel Rinascimento. Guide Storica e Critica, Roma-Bari, 1979; y W. H. WoORHARD, Studies in Education in the Age of the Renaissance. 1400-1600, Cambridge, 1924. 
(al menos en su forma de pensar) del antiguo alfabeto romano, con el fin de provocar el retorno al gusto clásico y revivir la elegancia de las viejas escrituras librarias. Esta "escritura antigua» que se hace común y se difunde en los manuscritos - a la que erróneamente aluden los humanistas- no fue, precisamente, la "romana" sino la letra "carolina" de los siglos $\mathrm{IX}$ al $\mathrm{X} \|$ cuyos códices y modelos descubrieron, estudiaron y volvieron a copiar -reproduciéndolos parcial o totalmente- los humanistas" ${ }^{20}$.

\section{NOMENCLATURAS}

Sin duda, entre los diversos nombres con que se la ha denominado, el de mayor aceptación es el de «humanística", término acuñado y propagado por los grandes paleógrafos italianos de la centuria pasada y actual -Paoli, Schiaparelli o Federici- ${ }^{21}$, y que hoy es prácticamente aceptado por todos.

Por contra, y debido a su significado más amplio, algunos autores ingleses y alemanes propugnan la acepción de "renacentista", puesto que durante el Renacimiento (siglos XIV-XVI) existen distintos tipos. Recordemos, como nos dice García Villoslada, que si el «Humanismo» fue un fenómeno primariamente italiano, imitado luego por los demás países, no se puede decir lo mismo del Renacimiento, que fue propio de toda Europa y significó la natural evolución y el tránsito histórico de la Edad Media a la Moderna. Los humanistas son hombres del Renacimiento, en cuanto que viven en época renacentista, pero no son sus únicos representantes, ni alcalzarán la altura de los pensadores, filósofos y artistas tan importantes como: Ockham, Nicolás de Cusa, Maquiavelo, Miguel Angel, Donatello, Leonardo, Copérnico, etc.

También, se la ha llamado "antigua" ("littera antiqua", "lettera al'anticha»), «majestuosa" y "venerable», "gótica redonda" («littera rotunda»), "de fácil lectura" ("legibilis") o simplemente "redonda", pero sin duda con menor éxito y difusión que los calificativos expuestos en primer lugar, que son los que han prevalecido.

En España, durante un largo período de casi 200 años los nombres más arraigados fueron el de «itálica", empleado ya en el siglo xVIII por

20 J. Mazolenni, Paleografia e Diplomatica e Scienze Ausiliare, Nápoles, 1970, p. 176.

21 Quizás sean G. CENCETTI y A. PETRuCCI los autores italianos que más número de páginas han dedicado al análisis de esta escritura en sus manuales: Lineamenti di storia della scrittura latina (Bolonia, 1954, pp. 259-352) y Breve storia della scrittura latina (Roma, 1989, pp. 165-184), respectivamente. 
Terreros, y el de «bastardilla» ${ }^{22}$. Hasta 1925 aproximadamente, en tiempos de Muñoz y Rivero, el de "itálica" fue el nombre más generalizado y empleado en todas las publicaciones. En España la consagración del término "humanística» se debe, sin duda, al P. García Villada. El fue quien comenzó a emplearlo y, posteriormente, se adoptó sin reservas en casi todos los tratados y manuales de los distintos especialistas españoles, como Millares, Floriano, Canellas y Arribas ${ }^{23}$.

\section{ORIGEN Y DESARROLLO DE LA ESCRITURA HUMANISTTICA}

Hay que considerar que la propia crisis de la escritura "gótica" constituye el punto de arranque de la sustitución escrituraria a que me vengo refiriendo ${ }^{24}$. La excesiva proliferación y sobreabundancia de tipos dentro de la escritura "gótica», - por poner un solo ejemplo, cito a Hajnal, quien aludiendo a los diplomas del siglo xill, distingue más de 30 tipos de escritura "gótica" de cancillería, diversificados a su vez en numerosas variantes- dió lugar, en toda Europa, a una especie de manierismo gráfico en las formas más caracterizadas de esta escritura cada vez menos funcional por complicada y difícil ${ }^{25}$.

El manierismo de los escribas que, con el fin de aumentar sus ganancias, trazan letras sugerentes, pero de rasgos semejantes, da como resultado un auténtico confusionismo gráfico, frente al cual Petrarca (13041374) se opone de forma decidida, creando para su propio empleo una escritura clara, basada en la «littera antiqua", que en su época suponían "romana", pero que en realidad era la "minúscula carolina" de las centurias IX a la XII, como ya he dicho. Claro que, aunque desacertado este juicio de Petrarca, no lo era del todo, si se tiene en cuenta que la escritura "carolina" representa el renacimiento de la "minúscula romana" ${ }^{26}$.

A Petrarca le molesta la letra "vaga y exuberante" de los escritores de su época, más atentos a complacer a la vista que a facilitar la lectura, y por eso reclama una letra precisa, sobria, límpida: "castigata e clara"

22 Esta acepción es más apropiada para el periodo contemporáneo (segunda mitad del siglo xVII al $x x$ ), en el que se pueden diferenciar las escrituras atendiendo, más que a la propia grafía, a su nacionalidad o su país originario. De esta manera, se puede hablar de letras "bastardillas": española, inglesa, francesa, italiana, alemana, etc., cada una con sus específicas características y connotaciones.

${ }_{23}$ Paleografia y Diplomática, vol. II, Madrid, 3." ed., 1998, p. 67.

24 D. THOMAS, "What is the origin of the "scrittura umanistica"?", Bibliofilia, LIII (1951), pp. 1-10.

25 E. CASAMASSIMA, "Lettere antiche: Note per la storia della riforma grafica umanistica", Gutenberg Jahrbuch, 39 (1964), pp. 13-26.

26 S. Rodicio, La escritura humanistica y su extensión a Hispanoamérica, Madrid, 1995, pp. 8-9. 
-dice él- que entre por los ojos sin esfuerzo y que se insinúe más allá de los ojos "que, destacando los rasgos diferenciales de cada grafía sobre los comunes y uniformes, busca ante todo la expresividad gráfica, aunque sin renunciar a los valores de belleza proclamados por una nueva estética capaz de admirar la majestad de la letra antigua" ${ }^{27}$.

Petrarca, iniciador de la reforma gráfica, trata de conseguir que el lenguaje escrito esté en consonancia con el lenguaje hablado del hombre perteneciente a aquella "sociedad nueva", surgida recientemente. De todas las maneras, conviene advertir que, ya antes, Lovato Lovati y Landolfo de Colonna realizaron un primer intento de imitar la escritura "carolina» en Padua y en Aviñón, respectivamente.

Para llevar a cabo estos proyectos e ideales renovadores petrarquinos nada más práctico que el estudio y utilización personal de la escritura antigua y su divulgación y proclamación, por razón de su practicidad, sencillez y belleza, en escritos y discursos. Esta idea y propósito de llevarla a la práctica con la mayor perfección posible los expone Petrucci-, recomenrigida a Bocaccio en 1366 -como recoge el prof. Petraci- «no me refiero dándole se aparte decididamente de la escritura articiosa: relajada y exu-dice Petrarca - a la letra fatigante y artificiosa - por lo relajad de exuberante en rasgos, cual es la de los copistas o más bor dañarla y cansarla, tra época, que embelesa a la vista au otro fin distinto de leer- sino a otra letra de rasgos sobrios, precisos y claros que se mete por los ojos, de la que no podrás decir que omite ningún rasgo ortográfico ni absolutamente nada referente a la gramática". Es más, ya anteriormente -en 1355cuando le agradece el regalo de un códice escrito en letra "carolina" del siglo XI (las Enarrationes in Psalmos, de San Agustín), Petrarca se muestra entusiasmado no sólo por la elegancia del códice, a pesar de la sobria ornamentación, sino también por la majestuosidad de la leta antigua, de tal modo que "cuando clavo los ojos en él, a modo de golondrinas sedientas, no logro retirarlos hasta no haber saciado la sed" ${ }^{28}$.

Principales escuelas y promotores de la «humanística»

Pero, como acabo de decir, Petrarca no llegó a estructurar la escritura "humanística». Quizá haya que considerarle pionero y creador, entre los humanistas, de una nueva escuela, pero fueron sus discípulos y admira-

27 A. Petruccl, «La scritura di Francesco Petrarca", Studi Medievali, 8 (1967), pp. 934-938.

28 Ibid., pp. 936-939. 
dores humanistas quienes, aparte de alabar el nuevo método escriptorio y sistema escriturario, lo imitaron y desarrollaron con gran eficacia ${ }^{29}$.

En ninguna otra parte el terreno y condiciones eran tan propicias como en Italia para realizar estos cambios gráficos. La escritura "libraria» italiana, aun participando de las características generales de la "gótica", había mantenido la redondez de la minúscula precedente, y algo parecido ocurría con la escritura "cancilleresca", máxime con la empleada en la cancillería pontificía, que se servía de tipos bien caracterizados dentro de la escritura «minúscula de transición» ${ }^{30}$.

Es precisamente en los círculos humanísticos de Florencia donde por estas fechas, se establece una corriente de innovación gráfica que culminará en la letra "humanística caligráfica», reservada no sólo a libros sino también a documentos de cierta relevancia y solemnidad. La búsqueda de códices carolinos altomedievales con textos de obras de autores clásicos - procedentes, por lo general, de las grandes abadías benedictinas, donde habían sido copiados durante los siglos $\mid X$ al XII- constituye el punto inicial de partida de esta reforma gráfica renacentista. Por consi-

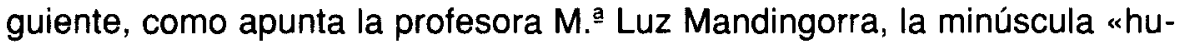
manística» - la "antiqua»-, fue una escritura de élite, cuya difusión mantiene gran paralelismo con la cultura docta de la que era expresión. Lo reducido de su ámbito social se debía, sin duda, a la función que se le reservaba -el libro humanístico era un libro de lujo, elegante y costoso, al que se incorpora además de la ornamentación, el gofrado, diversidad de orlas, miniaturas, profusión de dorados, etc.-, pero también al hecho de que su enseñanza se encontrara, en los inicios, ausente de las escuelas y centros docentes, por lo que su reproducción sólo se efectuaría imitando, bien modelos altomedievales escritos en la «minúscula carolina», bien modelos humanísticos coetáneos. Cuando la enseñanza de la escritura «humanística" se introdujo en los centros escriptorios y escuelas: "bottegue scrittorie", su difusión se aceleró, al tiempo que se abría la posibilidad de proceder a una modificación del canon ${ }^{31}$.

\footnotetext{
29 Cabe destacar la reciente obra de J. F. Maillard, J. KeCskemeti y M. Portalier, L'Europe des Humanistes (xive-xvile siècles) (París, 1995), en la que presentan la bio-bibliografía de unos 2350 humanistas, por lo que se convierte en una interesante herramienta de referencia y consulta.

30 T. FRENTZ, “Das Eindringen humanistischer Schriftsformen in die Urkunden und Akten der Päpstlichen Kurie im .15. Jahrhundert», Archiv für Diplomatik, 19 (1973), pp. $287-418$ y 20 (1974), pp. 384-506.

31 M. L. MANDINGORRA, “La escritura humanística en Valencia: su introducción y difusión en el siglo xv", Estudis Castellonencs, 3 (1986), pp. 5-94.
} 
Es preciso advertir, no obstante, que al lado de los ricos libros litúrgicos, devocionales e históricos, v. gr. "libros de horas", "misales", "breviarios", "homiliarios", "biblias", "crónicas»..., auténticas joyas artísticoculturales, y de los tratados clásicos de teología, derecho, medicina y astronomía o de contenido e inspiración religiosa, literaria, poético-narrativa, política, etc., confeccionados de encargo tanto para reyes, príncipes y nobles como para la alta burguesía, clases dirigentes, dignatarios eclesiásticos y centros culturales: Universidades, bibliotecas, catedrales, monasterios..., existen otros tipos de libros, comúnmente más corrientes y sencillos: el «libro universitario", sometido al control y normativa estatutaria de cada Universidad, y las traducciones para estudiosos e intelectuales, principalmente greco-latinas y árabes, de obras de singular representatividad como lo eran las de Platón, Aristóteles, Cicerón, Tito Livio, San Agustín, San Juan Crisóstomo, San Gregorio, Santo Tomás de Aquino, Averroes, etc., escritas bien en "gótica caligráfica redonda", "libraria cursiva", "textual", "cortesano-humanística" o "híbrida", bien en alguna de las «humanísticas", principalmente en "gótico-humanística" o en «humanística redonda" y "cursiva», reservándose la "cancilleresca", "corriente" $y$ «mercantil» para los documentos.

Consecuentemente, era previsible que tanto en Petrarca como en otros coetáneos suyos aparecieran similares inquietudes y propensiones. Entre ellos, además de su discípulo Giovanni Bocaccio -que a partir de 1350 tiende al redondeamiento de los trazos y al equilibrio ordenado de las formas según el modelo petrarquista, como expone la Dra. Alvarez Márquez-, destaca la triada compuesta por Coluccio Salutati, Niccolo Niccoli y Poggio Bracciolini ${ }^{32}$. El primero de ellos, C. Salutati (1331-1406) - secretario de la república de Florencia - escribe en letra "rotunda", parecida a la de Petrarca, y logra reunir y, en parte, copiar cerca de un centenar de códices de obras cásicas pertenecientes a los siglos IX al XII. El fue quien propuso como modelo su propia escritura, es decir, la letra "carolina», a la que da el calificativo de «antiqua littera» por considerarla propia de la antigüedad clásica romana ${ }^{33}$. A principios del siglo xv pide a un amigo le facilite las Cartas de Abelardo en clitera antica" con estas palabras: "si de antiqua littera haberi possent, libentius acciperem» («si las hallases escritas en letra antigua las recibiría aun con más gusto»), "nulle quidem littere sunt meis oculis gratiores" («para mi gusto y a mis ojos no hay letra [escritura] que me agrade más).

32 C. Álvarez Márouez, op. cit., p. 27

33 Ver figura 1. Ejemplo de letra "humanística redonda", trazada por Coluccio Salutati, del 26 de junio del año 1392. Contiene una carta de la República de Florencia al Papa Bonifacio IX. Se conserva en la Biblioteca del Vaticano (Cappon. 147, c). 
Niccolo Niccoli (1364-1437) —de quien Vespasiano da Bisticci decía, en su Vite di uomini illustri, que "ningún libro por bueno que sea le agradaba, si no estaba escrito en letra antigua»- prolonga esta corriente hasta la generación siguiente. Amigo de Bracciolini y fundador de la escuela escriptoria de Florencia, Niccoli no fue escriba profesional ni firmó los manuscritos que se le atribuyen; las obras manuscritas identificadas y tenidas como suyas son copias hechas entre 1421 y 1432 y, en consecuencia, posteriores a la ya reseñada de su amigo e incluso a casi todas las que éste produce en un lapso de 25 años. Empleaba caracteres humanísticos cursivos con ligeras reminiscencias góticas, lo que le convertía en rival de Bracciolini en cuanto al sistema escriturario y le hacía tener un estilo inconfundible ${ }^{34}$.

$Y$ es el humanista Poggio Bracciolini (1380-1459) -secretario de diversos pontífices- quien la lleva a su perfección y acabamiento en un códice del año 1402-1403 (aunque el prof. Battelli, en sus Lezioni di Paleografia, retrasa la fecha hasta 1408 ), considerado por varios autores como «el primer manuscrito datable en escritura humanística" ${ }^{35}$. Se trata del “Códice Laurenziano Strozziano 96", que contiene el tratado “De Verecundia" de Coluccio Salutati ${ }^{36}$.

Los manuscritos copiados por Bracciolini son auténticos modelos de "carolina" espontánea y elegante, resaltados con capitales cuadradas para las iniciales. Dicha letra pasa de los códices a los documentos, sustituyéndose lentamente la "gótica cursiva» por otro tipo, también cursivo pero de corte humanístico, que muchos denominan «humanística cursiva».

A raíz de su partida de Florencia hacia Roma para asumir la "Secretaría Pontificia de Breves», se tienen noticias, por su correspondencia, de que Poggio Bracciolini, con el fin de atender su biblioteca, costeó la formación de tres copistas, a quienes él enseñó la "littera antiqua". Por otra parte, consta documentalmente la sucesión en Florencia de tres generaciones de copistas, representadas respectivamente por Antonio di Mario, al que Ullman atribuye al menos 42 códices, firmados entre 1417 y 1456, escritos en letra muy caligráfica, alta y estrecha; Gerardo del Ciriaggio, a quien reconoce 34 códices entre 1447 y 1472, todos de letra

\footnotetext{
34 Ver fig. 2. Muestra de «litera antica» en "humanistica cursiva" con expresiones griegas en caracteres mayúsculos de Niccolo Niccoli fechada en 1427, con texto de Celso. Biblioteca Nacional de Florencia (Conv. Soppr. I, IV).

35 Por ejemplo, J. Stiennon, Palégraphie du Moyen Age, París, 1973, p. 123.

36 Ver fig. 3. Manuscrito Laurenziano Strozziano 96, del año 1402-03, de mano de Poggio Bracciolini, conservado en la Biblioteca Laurenziana de Florencia (Ms. Laur. Strozz. 96). Muestra de "humanistica redonda".
} 
más estrecha que la de Poggio, aunque siguiendo su tradición, y caracterizada por su moderado claroscuro y por el enderezamiento de los astiles ${ }^{37}$; $y$, finalmente, Antonio Sinibaldi, del que actualmente se conocen al menos 34 códices, fechados entre 1461 y 1499, y escritos con letra elegante y muy bella, basada en un sutil y moderado claroscuro y ligera sinuosidad en los astiles ${ }^{38}$.

El consejero de Cosme de Médicis y del papa Nicolás V, Vespasiano da Bisticci (1421-1498) —que se establece en Florencia como vendedor de códices y libros con librería o establecimiento propio y, al mismo tiempo, como "tipógrafo" o elaborador y confeccionador (estacionario) de libros de encargo, con copistas a su servicio en Italia, Hungria, Alemania, Portugal, Inglaterra, etc. - completa el sistema y gremio librero en Florencia en la segunda mitad del siglo $\mathrm{xv}$, dando preferencia, en cuanto a uso, a la «letra antigua».

Fernando I Ferrante, hijo de Alfonso $V$ de Aragón y rey de Nápoles desde $1458{ }^{39}$, figura entre los principales clientes de Bisticci. Durante su reinado, continuando el mecenazgo de su padre ${ }^{40}$, tiene lugar el gran florecimiento y desarrollo de la «Escuela napolitana de letra antigua», organizada al parecer por Pietro Strozzi. En ella trabajaron, entre otros, el citado Antonio Sinibaldi, Giovanni Marco «el Cínico" -que escribió 71 códices-, Giovanni Rinaldo Mennio -que redactó 25 códices-, Giacomo Curlo, Pietro Ursuleo y Clemente Genovesi, según estudio documentado de Luisa D'Arienzo ${ }^{41}$.

A esta "Escuela napolitana" de copistas en "littera antiqua", de capital importancia para la transmisión y trasvase de dicha letra a la península lbérica (Corona de Aragón), estuvieron también vinculados Niccolo Perotto, Antonio Becadelli y Giovanni Pontano, sin contar otros célebres humanistas protegidos por la corte napolitana, destinados no sólo a la composición y escrituración de códices y manúscritos sino tambien a la elaboración y expedición documental y de interrelación oficial. Baste citar a algunos: Lorenzo Valla, Bartolome Fazio y Eneas Silvio Piccolomini.

37 Ver fig. 4. Ejemplo de letra "humanística redonda" de pura traza poggiana de Gerardo del Ciriaggio, fechado en 1454 y conservado en la Academia Nacional de Roma (Ms. Cors. 44, B, 40).

38 S. Rodicio, op. cit., pp. 10-11.

39 Sin embargo, otros autores identifican a este Monarca con el futuro Fernando el Católico. Véase S. Rodicio, op. cit., p. 11.

40 llustrativo sobre esta materia es el celebrado estudio: A. SoRIA, Los humanistas de la Corte de Alfonso el Magnánimo, Granada, 1956

41 L. D'ARIENZO, «Alcune considerazioni sul passagio della scrittura gotica all'umanistica nella produzione documentaria catalana dei secoli xIV e XV". Studi di Paleografia e Diplomatica, Padua, 1974, p. 222. 
Aparte de las escuelas mencionadas, hubo otras, sin duda de menor relieve y significado, pero importantes y decisivas en la reproducción de códices, a las que se difundió con rapidez la "humanística", paralelamente a la transmisión de la nueva cultura docta. Dichas escuelas de segundo orden, influenciadas principalmente por la florentina, se ubican en distintas ciudades italianas de cierto relieve económico, social y político. Así sucede, por ejemplo, en Urbino, ciudad en la que el juez Federico Veterano compiló un catálogo de 606 códices latinos y 93 griegos que atesoraba la biblioteca de su señor, el duque Federico de Montefeltro (1442-1472) -hoy en la Biblioteca Apostólica Vaticana-, suministrados esencialmente por el taller de Vespasiano da Bisticci.

Sabemos que Roma, ya en 1429 había acogido la "letra antigua» como se observa en el Códice Vaticano 1862 de la Germania de Tácito, y un dato aun más importante: que en pleno siglo XV esta "littera antiqua" acaba por imponerse sin modificaciones en gran parte de documentos de cancillería, si exceptuamos las bulas, hecho decisivo en cuanto a su difusión, ya que por influjo de la principal cancillería de la Iglesia-Romana (capital de la cristiandad), su uso se extendió a otras cancillerías eclesiásticas y civiles. Junto a Bartolomeo Sanvito, quizá el humanista romano más célebre del siglo xv sea Pomponio Leto (1428-1498), continuador del sistema de su maestro Lorenzo Valla y autor de un Compendio Storico, que abarca desde Gordiano a Justino III ${ }^{42}$.

Con características propias, tendentes a una mayor fidelidad al tipo de la "semigótica", se producen códices humanísticos en Ferrara, coincidiendo el período de mayor esplendor bajo el dominio y patrocinio de la célebre familia nobiliaria de la Casa del Este (1450-1471). Se considera obra maestra de la escuela ferranense la Biblia de Bors, escrita el año 1461 por los amanuenses Pietro Maroni y Bernardo de Alemania. Ambos escribas serán imitados y seguidos por un digno émulo: Nicolo Mascarino.

Hacia 1490, ahora en Bolonia, descuellan Pierantoni Sallando y Gerolamo Pagliarolo, quienes trazan una "littera antiqua" solemne y de curvas suavizadas, por lo general de letras anchas, pero más serena y de mayor módulo y con astiles más pronunciados que los modelos florentinos ${ }^{43}$.

En Milán destacan como principales copistas de este tipo de letra Cosimo Raimondi Cremonese y Francesco Bossi (obispo de Como), sien-

42 G. MuzzıoLI, "Due nuovi codici autografi di Pomponio Leto", Italia Medioevale e Umanistica, II (1959), pp. 337-341.

43 S. Rodicio, op. cit., pp. 12-13. 
do importante la biblioteca formada por las familias de Visconti y de Sforza. En Cesena, debido a la iniciativa de Domenico Malatesta Novello, se formó otra espléndida biblioteca humanística, la cual perdura en la actualidad. Otras ciudades: Verona, Mantua, etc., con pequeños círculos culturales, acogen escuelas en las que se escriben interesantes tratados tanto en letra "humanística caligráfica» como "cursiva».

Cuando estos tipos humanistico-renacentistas consiguen expandirse por toda Italia ${ }^{44}$ con un alto grado de canonización y tipificación, los modelos italianos del siglo $\mathrm{x} v$ se difunden por toda Europa, produciéndose a lo largo de esta centuria decimoquinta, según los países, nuevas modalidades gótico-humanísticas, que desembocan en las típicas «humanísticas» de las centurias siguientes.

En la Península lbérica se siguen modelos italianos, que se introducen, por razones políticas de dependencia, primero en la Corona de Aragón. Para Luisa D'Arienzo los primeros ejemplos de «minúscula cancilleresca" con fuerte influencia "humanística" se observan ya hacia 1435 , concretamente en la correspondencia mantenida entre Alfonso $V$ con sus funcionarios de la península ${ }^{45}$. La nota más característica de esta "humanística cursiva cancilleresca" probablemente sea su trazado intermedio entre la "antigua» y la «itálica» ${ }^{46}$.

En Castilla se va introduciendo en diferentes etapas. Sus inicios tienen lugar tras la unificación penínsular y, de modo claro y definitivo, durante el reinado de Carlos V.

Con relación a los territorios de Ultramar (Hispanoamérica y Filipinas) la escritura presenta características semejantes, en cuanto a morfología y evolución, a las de la metrópoli ${ }^{47}$.

Me permito citar, por su gran significación, los códices post-cortesianos trazados en una escritura mixta ${ }^{48}$. En primer lugar, el Codex Vindobo-

44 Sobre esta cuestion puede consultarse la obra: A. C. LA MARE, The Handwriting of Italian Humanists, Oxford, 1973.

45 L. D'ARIENZO, Op. cit., p. 222.

46 A. Millares, Tratado de Paleografía Española, vol, 1, 3." ed., Madrid, 1983, p. 240.

47 Así lo manifiesta la profesora M." Asunción VILAPLANA en su interesante estudio: "El desarrollo de la escritura en la documentación hispanoamericana", Documentación y Archivos de la Colonización Española, II (1980), pp. 337-348.

48 El estudio y análisis de estos códices indianos es el tema central de las obras siguientes: J. Alcina, Códices Mexicanos, Madrid, 1992; L. AzCuE, Códices indígenas, México, 1966; J. Dominguez Bordona, Manuscritos de América, Madrid, 1935; N. Gutierrez Solana, Códices de México, 2. ed., México, 1988; L. Manalque, Los códice de México, México, 1979; y J. Tudela, Los Manuscritos de América en las Bibliotecas de España, Madrid, 1954. 
nensis, acabado en 1527 y conservado en Viena, que reune varios documentos complementarios de las «Cartas de Relación» de Hernán Cortés, escritos por once manos distintas que utilizan una escritura mezcla de "procesal» y "humanística». El Códice Mendoza, compuesto por orden del virrey Antonio de Mendoza (1535-1550) y que se conserva en Oxford, escrito en letra pictográfica indígena de gran valor artístico; a cada imagen le acompaña su significado en escritura «humanística cursiva», con influencia de la «procesal». El Códice Tudela —del año 1553 y que forma parte de los llamados "Códices Antológicos», entre otros, el Vaticano-Ríos (en El Vaticano), el Magliabecchiano (en Florencia) y el Telleriano-Remense (en la Biblioteca Nacional de París) - está trazado en una escritura «mixta» en la que predominan los elementos procesales sobre los humanísticos ${ }^{49}$. El Códice Osuna, redactado entre 1565:1566, consta, como el Mendoza, de pinturas indígenas y de escritura "mixta", en este caso predominando la «humanística cursiva» con inclinación hacia la derecha. Algo parecido puede decirse del Códice Cabezón, conservado en la Real Biblioteca de El Escorial, en cuanto a la escritura empleada y fecha de elaboración. El Códice Durán, acabado en 1579 por el dominico Diego Durán y conservado en la Biblioteca Nacional de Madrid, es otro ejemplo de escritura «mixta», predominando considerablemente en él la «humanística cursiva».

Posteriormente se impone en Hispanoamérica la escritura «itálica», con ejemplos prototipos como el Códice Badiano (traducción latina que Juan Badiano hizo de un libro sobre hierbas medicinales usadas entre los indios, escrito en nahuatl por Martín de la Cruz), que se conserva en El Vaticano y está escrito en letra «itálica» perfecta muy caligráfica, y la Nueva Crónica y Buen Gobierno, de principios del siglo XVII, escrito por el mestizo Felipe Huamán en lengua española muy pobre con mezcla de quechua y, en cuanto a escritura, en letra «itálica» 50.

En Francia la «humanística», por lo general, es letra inclinada y cabeceante, al estilo de la italiana, pero de trazo más complicado. Se consolida, ai igual que en España, durante la centuria decimosexta a partir de $1550{ }^{51}$. De la primera generación de humanistas franceses que emplean

49 Ver fig. 5. Fragmento del Códice Tudela - fol. 23r-, escrito en shumanística corriente" con elementos procesales, del año 1553 y conservado en el Museo de América de Madrid. Se trata de un libro de $210 \times 154 \mathrm{~mm}$., encuadernado en cartón, forrado de pergamino en sus dos tapas y que consta de 118 folios, con dos hojas de guarda. Todo él ha sido escrito por una sola mano.

50 S. Rodicio, op. cit., pp. 17-22.

51 Consúltense los estudios: H. Michaud, La Grande Chancellerie et les Ecritures Royales au Seizième Siécle (1515-1589), París, 1967; E. Poulle, Paléographie des Ecritures Cursives en 
esta letra (comienzos del siglo xv) destacan Nicolas de Clamanges y Jean de Montreuil ${ }^{52}$.

En Inglaterra, que es donde antes se adoptan los caracteres humanísticos, éstos son más caligráficos, alcanzando carta de naturaleza a comienzos del siglo XVI. Los propios profesores de la celebérrimas Universidades de Cambridge y Oxford, tras residir en Italia, son los encargados de introducirlos en su país ${ }^{53}$.

Finalmente, en Alemania, la "humanística» presenta reminiscencias de su típica gótica cursiva. Aunque en el siglo xv existió una discreta penetración ${ }^{54}$ (su escritura "cancilleresca" se denomina "fraktur»), no será hasta dos siglos después cuando coexista con la "cursiva cancilleresca" ("Kanzleischrift») y sólo en el siguiente (siglo XVIII) cuando se impone la «Kurrentschrift», es decir la escritura «humanística corriente» 55 .

\section{ETAPAS BÁSICAS DE SU EVOLUCIÓN}

Me he referido anteriormente al origen histórico y posterior desarrollo gráfico de los modelos humanísticos. Volviendo sobre el origen gráfico, la observación y estudio estructural de las escrituras "góticas" nos muestran que cada vez son más cursivas y manierísticas - hasta el punto de que, refiriéndose a la "procesal», Cervantes en El Quijote, Santa Teresa en sus Cartas, Luis Vives en sus Diálogos, Nebrija o Antonio de Guevara, por citar sólo algunos, la definieron como "letra infame", "diábolica", "letra que no entenderá ni Satanás", "no son letras, sino desvario y desconcierto de letras" y "parece imposible que sean leídas por ojo humano, ni siquiera con lente de gran aumento»-

\footnotetext{
France du xve au xvIIe Siécle, Ginebra, 1966; y Ch. Samarán, "Cursives françaises des $\left.x V^{\circ}, x V\right]^{\theta}$ et XVII siécles, Journal des Savants (1967), pp. 129-153.

52 G. OuY, "Jean Montreuil et l'introduction de l'écriture humanistique en France au début du $x v^{e}$ siècle", Litterae textuales, 4 (1976), p. 54.

${ }_{53}$ Son interesantes para este tema las obras siguientes: W. J. BLUNT y W. CARTER, Italic Handwriting: Some Examples of Everyday Cursive Hands, Londres, 1954; A. J. FAIRBANK y B. WOLPE, Renaissance Handwriting: an Antology of ltalic Scripts, Londres, 1960; A. S. OsLEY, Scribes and Sources. Handbook of the Chancery Hand in the 16th Century, London-Boston, 1980; R. WEISs, Humanism in England During the Fifteenth Century, Oxford, 1967; y J. I. WHALLEY, English Handwriting, 1540-1853. An Illustration Survey, Londres, 1969.

54 Las figuras de Hartmann Schedel y Hieronymus Rotenpeck sirven de ejemplo y referencia a 10 expuesto.

${ }_{55}$ Pueden verse los estudios: Renaissance und Humanisten Handschriften, Munich, 1988; y G. MENTZ, Handschriften der reformationzeit, Bonn, 1912.
} 
A raíz de las transformaciones sociales, culturales y del cambio de mentalidad acaecidas durante el siglo Xv, se altera, como hemos visto, el modelo escriturario. Dicha modificación obedece no sólo a motivaciones estéticas sino también a que la escritura se ha convertido en símbolo principal de una nueva era, distinta de la precedente en cuanto al modo de ser, pensar y valorar. Mirando al pasado, recuerdan que la escritura "carolina" estaba bien hecha, era funcional y sencilla de leer; de ahí que la toman como modelo. Esto explica que la "humanística" no sea otra cosa, desde el punto de vista gráfico, sino la "carolina» renacida, restructurada y renovada y, desde el cultural e ideológico, el símbolo de una nueva cultura clásica heredada del mundo romano, pero aplicada al momento histórico-social del Renacimiento.

Aunque en la promoción de la letra "humanística" se tiene en cuenta el alfabeto gótico, se coloca junto a él otro, calcado en el romano, para así revitalizar y revivir el gusto clásico. Los humanistas, volviendo la mirada a los siglos $\mathrm{I}, \mathrm{x}$ y $\mathrm{XI}$, descubren y admiran lo bueno y bello de aquella grafía con el fin de imitarla, desarrollarla y perfeccionarla. En una palabra, quieren revivir la escritura "carolina", pero con más ritmo y acomodada al "nuevo espíritu" que fluye en la sociedad y los ambientes renacentistas. De todo ello surge una escritura que, a juicio de los máximos especialistas, es en un $65-70 \%$ aproximadamente "carolina" $y$, en un 30-35\%, "gótica", según se trate de redondas caligráficas o de cursivas.

La escritura «humanística» evolucionada y desarrollada hasta la actualidad, sigue siendo hasta hoy - por supuesto con ligeras modificaciones-el medio normal de que nos servimos cuando escribimos a mano. ¿Por qué se ha mantenido tanto tiempo? La explicación es elemental. Estamos ante una escritura de trazado rápido, sencilla y de fácil lectura y comprensión. Esta circunstancia influye tanto en la docencia como en el aprendizaje, ya que no presenta grandes dificultades, pues se trata de tipos de escritura parecidos a los actuales, según apuntamos antes. Los calígrafos, en sus escuelas, enseñaron preferentemente este tipo de escritura, al principio modelos redondos y más tarde cursivos: Luis de Henricis, Mario Antonio Tagliente, Juan Bautista Palatino, Ugo di Carpi, Baustista Creci, etc. -entre los italianos- y Juan de Iciar, Pedro de Madariaga, Francisco Lucas, Ignacio Pérez, Pedro Díaz Morante, José Casanova, Francisco Javier de Santiago y Palomares, Torcuato Torío, etc. -entre los españoles-.

En la letra "humanística" o «itálica» —novedad del Renacimiento que muchos tratadistas llaman «bastarda" y que Juan de Icíar califica de "primera letra entre las cancillerescas"- ve el profesor Marichal la conjunción entre el ideal humanístico florentino, representado por la virtud ("virtuo- 
sismo") cívico-cultural que revela al hombre como medida del mundo, frente a la autoridad ("auctoritas») encerrada en las ciencias filosóficas y teológicas, y por cierta suavidad ("suavitas"), con leve grado de mundanidad, que debe compaginarse con un mínimo de gravedad y seriedad ("gravitas") y con cierta honestidad ("honestas"), en atención -como indica el mencionado autor- a la "seriedad y dignidad de su predecesora y madre la carolina, letra que habia imperado siglos antes" y cuyos últimos destellos alcanzan a la «humanística» ${ }^{56}$.

La letra "humanística» hizo su entrada triunfal en todas las cancillerías, curias, escuelas y aun escribanias, no sólo por su sencillez y facilidad de ejecución, que la hacía, por un lado muy rápida y, por otro, nítida y legible, sino también por su singular belleza; por idénticas razones tiene gran aceptación entre el pueblo; y lo mismo ocurre en la escritura de libros o caracteres de imprenta que son simple adaptación.

En la evolución de la escritura "humanística» suelen señalarse tres momentos fundamentales:

a) El primero corresponde al período de la escritura "gótica-prehumanística". Se puede datar a finales del siglo XIV, coincidiendo con la figura de Petrarca. Se caracteriza por mantener todavía en su trazado formas más redondeadas que lo habitual, "curvas contrapuestas" y otros elementos y rasgos propios de la escritura "gótica". Con la introducción "prehumanística" se dan los primeros pasos para la reforma caligráfica, a base de ir introduciendo en los modelos góticos elementos de la vieja "carolina" 57 .

b) Un paso más en el proceso gráfico transformativo, correspondiente al segundo momento, y nos encontramos ya con la escritura "gótica-humanística" - "fere-humanistica»-, en la terminología del Card. Ehrle y "semi-humanística" - según Schiaparelli y otros autores-, cuya promoción, impulso y difusión corresponde - dentro del siglo $x v-$ a Niccolo Niccoli, íntimamente ligado a la técnica y corriente escriptoria de Coluccio Salutati iniciada algunas décadas antes ${ }^{58}$.

56 R. MARICHAL, "La escritura latina y la civilización occidental del siglo I al siglo XVl", La escritura y la psicología de los pueblos, 2. ed., México, 1971, pp. 233-241.

57 Ver fig. 6. De sui ipsius et multorum ignorantia, cbra en "gótico-prehumanística» escrita por Petrarca en 1370 y conservada en la Biblioteca Apostólica Vaticana (Ms. Vat. Lat. 3359). Es esencialmente gótico, además de su ductus, el trazado de gruesos y perfiles, las abreviaturas numerosas, la propensión a repliegues angulosos y el encolamiento entre trazos redondeados inmediatos. Denota el aire humanistico la tendencia redondeada de las formas.

${ }_{58}$ Ver fig. 7. Collationes decretorum concilii Basiliensis, obra conservada en la Biblioteca Nacional de París (Ms. Lat. 12. 101) y escrita el año 1433 por los notarios del concilio de Basilea: Galteri y Chesneloti. Fragmento en «humanística redonda" con elementos gotizantes. 
c) Finalmente $-y$ éste es el último peldaño del proceso evolutivo de la letra a que vengo refiriéndome-cuando en dicha escritura se prescinde totalmente de los rasgos típicamente góticos, estamos ya en la escritura "humanistica" pura. El primero en dar este paso gráfico (s. XV) fue el ya citado humanista florentino Francesco Poggio Bracciolini, si bien hasta pasado algún tiempo dicha letra y sistema no adquirirán carta de naturaleza ni tipificación definitiva.

\section{TIPOS DE LETRA HUMANÍSTICA TANTO LIBRARIA COMO DOCUMENTAL}

Una vez analizadas las distintas fases del proceso evolutivo y pasos de la "gótica" a la "humanistica", procedo a exponer los principales tipos de esta escritura. Partiendo de la clasificación y nomenclatura propugnada por el antiguo profesor de la Escuela Vaticana de Paleografía y Diplomática, Dr. Battelli, y en conformidad con la propuesta que él hizo en el coloquio celebrado en París el año 1953 sobre las distintas nomenclaturas de las escrituras librarias de los siglos $1 \mathrm{X}$ al $\mathrm{XV} \mathrm{l}^{59}$, propongo, como organigrama básico representativo de los principales y más caracterizados grupos con alto grado de canonización, los siguientes tipos: A) "Humanística redonda"; B) "Humanística cursiva"; C) "Humanística cancilleresca"; D) "Humanística corriente»; y E) "Humanística mercantil» y "notarial» 60 .

\section{A) Humanistica Redonda}

La escritura "humanística redonda" o "formada" -que algunos denominan «libraria», v. gr. Jole Mazzoleni, Giulio Battelli, etc. - no es sino la "carolina" restaurada en su sustancia y en muchos de sus accidentes, de tal modo que su imitación es tan manifiesta que raya en el servilismo. El medio cultural en que se desarrolla todavia deja un pequeño resquicio a los diversos tipos de escrituras "góticas" cuyo influjo sigue, aunque sea en el trasfondo, apenas perceptible.

Como características generales más destacables, comunes a la letra "humanística formada», señalo las siguientes: proporción, regularidad y, en

59 G. Battelli, "Nomenclature des écritures humanistiques", I Colloque International de Paléographie Latine, París, 1954, pp. 35-44.

60 Esta nomenclatura, habitual por otra parte, no es aceptada ni formulada por todos los especialistas en la materia. De este modo, la profesora Elisa Ruiz sugiere y plantea la denominación de "escritura humanistica derecha" para identificar la "humanística redonda" y «escritura humanística inclinada" para la "humanística cursiva", en atención a su apariencia externa. E. Ruiz GARCIA, "La escritura humanística y los tipos gráficos derivados", Introducción a la paleografía y la diplomática general, Madrid, 1999, pp. 151-152. 
muchos casos, redondez; nitidez y claridad gráfica a base de trazo sencillo y ágil, de manera que su trazado desarrolla formas verticales y curvaturas sin adornos ni arranques y, sobre todo, sin acabados ornamentales; reducción de abreviaturas; respeto y, a la vez, imitación de las formas caligráficas antiguas, concretamente de la "minúscula carolina libraria", teniéndose un cuidado especial en separar las palabras, uso correcto de los diptongos y aun de los nexos y ligados característicos o al menos de inspiración "carolina" (ct, et, st). En la segunda mitad del siglo xv la "humanistica redonda" o «libraria" alcanza su perfección, máxime cuando los caracteres italianos y parisinos pasan a la imprenta en los primeros libros (incunables), imponiéndose a los góticos de Gutenberg y a la propia manuscritología libraria ${ }^{61}$.

La "humanistica redonda" es la escritura de los bellos manuscritos producidos en el ambiente cultural de las cortes renacentistas italianas y, especialmente, en la de Florencia. Es también la letra empleada en las grandes oficinas productoras de manuscritos por encargo, como ocurre con la de Vespasiano da Bisticci. Ejemplares de estos manuscritos se encuentran en todas las grandes bibliotecas reales y principescas europeas, como la de Matias Corvino, rey de Hungría, o la de los Reyes de Aragón. La verdad es que de muchas de estas obras sólo se conservan fragmentos y es tal su dispersión que no resulta infrecuente encontrar ejemplares en las grandes bibliotecas regias o universitarias y, en particular, en la Laurenciana de Florencia y en la Vaticana ${ }^{62}$.

El modelo de "humanística redonda" -como he indicado antes-, además de utilizarse para escritura manuscrita, se usó también para libros impresos. En efecto, pasados los primeros momentos de esplendor de los impresores alemanes o flamencos, que utilizaron como modelo las "góticas" del siglo xv, al llegar la imprenta a los países mediterráneos, pronto se incorporó la "humanística redonda" a los modelos tipográficos.

Desde la segunda mitad del siglo XV, gracias a la protección de Juan de Torquemada, se imprimen los primeros libros en Italia, concretamente en el monasterio de Subiaco (año 1465), donde éste era abad ${ }^{63}$. Los impresores alemanes, Albert Pfister y Ulrico Han, realizan sus primeros trabajos en Italia en la segunda mitad del XV, pero con anterioridad (año 1466-67) ya se habian instalado en Roma, Pannartz y Sweynheim, tipógrafos pro-

61 Ver fig. 8. Modelo de letra "humanística redonda" del florentino Antonio Sinibaldi del año 1481. Manuscrito latino de la Biblioteca Vaticana (Urb. lat. 666), que contiene la obra de Prudencio.

62 S. RoDicio, op. cit., pp. 12-13.

63 No se debe equivocar la figura de este dominico (1388-1468) con la de su sobrino, el célebre Inquisidor Tomás de Torquemada (1420-1498). Véase el estudio citado de Sara Rooıcio (p. 13). 
cedentes de la saqueada Maguncia. Todos ellos adaptan su tipología tipográfica al modelo de la "humanística redonda», convirtiéndose Roma, poco después de Subiaco, en la sede principal de los más antiguos incunables italianos; sus tipos librarios, fundidos para los textos impresos, recibirán el calificativo de «tipos romanos". Muy pronto estos modelos pasarán a la península lbérica realizándose con ellos, en el último tercio del siglo $\mathrm{XV}$, las primeras impresiones de incunables en las ciudades de Segovia, Valencia y Barcelona, cada una de ella émula y aspirante a ser la primera. El ejemplo de los clérigos Conrado di Sweinheim y Arnoldo Pannartz fue seguido rápidamente por Nicolás Jenson en Venecia (a. 1471).

\section{B) Humanistica cursiva minúscula}

Hasta hace unos años se pensaba que esta escritura era una derivación de la «minúscula gótica notarial» italiana del siglo XIV que, bajo la influencia de la "carolina", elimina todo residuo de la contorsión del trazado. Pero investigaciones posteriores han permitido conocer sus orígenes con toda seguridad. Fue B. L. Ullman, en su obra citada, quien ratificó la hipótesis de Morison al identificar 9 manuscritos de Niccolo Niccoli que prueban que esta escritura estaba completamente desarrollada en el «quatrocento" (1420-35). Para muchos autores, entre otros: Jole Mazzoleni, N. Barone, etc., esta escritura procede de la "semigótica» de tradición «trecentesca", es decir, de la "gótica cursiva libraria" en el momento en que ésta había superado ya el período prehumanístico, a comienzos del XV, cuando los caracteres humanisticos habían desplazado paulatinamente los elementos góticos. En la península lbérica se generaliza su uso en la centuria decimosexta.

Como características principales de esta "cursiva minúscula humanística" destacan: el trazado de las letras con relación al renglón suele ser oblicuo y cursivo, de ahí que se escriba con más rapidez que la redonda; los astiles y los caídos son prolongados; la letra muestra en los astiles inclinación a la derecha con tendencia dextrógira, siendo más fina, ágil, viva y puntiaguda que la redonda. Asimismo es importante señalar que las letras de cada palabra tienden a unirse entre sí y que los nexos son mínimos y no dificultan la lectura ${ }^{64}$. Se trata, según Millares,

64 Ver fig. 9. Belli Civilis, obra de Marco Aneo Lucano, escrita por Pomponio Leto en 1470 y conservada en la Biblioteca Apostólica del Vaticano (Ms. Vat. Lat. 3285). Muestra de "humanística cursiva". 
"de una escritura inconfundible, elegante, esbelta..., con eliminación casi total de ligaduras" ${ }^{65}$.

Para no confundir esta "humanística cursiva» con la "gótica cursiva" pienso que sería mejor reservar el nombre de «humanística cursiva" sólo para aquellos tipos escriturarios en los que ya no haya, o sean muy escasos, los residuos gráficos de la "gótica". Si existiera una simbiosis de ambas -como con frecuencia sucede en Castilla y Aragón durante la segunda mitad del siglo $x V$ y comienzos del XVI-, quizá fuera mejor denominarla «cortesano-humanística», "aragonesa-humanística», etc., o viceversa, según el predominio de una u otra.

Pero, al igual que sucede con la "humanistica redonda", que no es exclusiva de libros, la minúscula cursiva no es exclusiva del ámbito documental, sino que se emplea también en el campo librario, y pasa a la imprenta, lo que favorece su total éxito y difusión. Respecto de esta letra dice G. Cencetti ${ }^{66}$ que es mejor llamarla con el nombre de «itálica», denominación aceptada, entre otros, por Emanuele Casamassima. Debido al impulso tipográfico y a los múltiples ejemplares impresos en «humanística cursiva" por el célebre tipógrafo, impresor y difusor veneciano Aldo Manuzio (a. 1499), a sus tipos y caracteres impresos se les dió el nombre de "caracteres aldinos" o "littera aldina".

Variantes de esta "humanística cursiva" son los caracteres cancillerescos, corrientes, notariales y mercantiles, que dan origen a nuevas "humanísticas»: "cancilleresca», "corriente», «notarial» y «mercantil».

\section{C) Humanística cancilleresca}

Recibe distintos nombres: "cancilleresca romana", "cancilleresca formada" (Delitsh) y "letra de breves" - como apunta Cencetti- por haber sido durante el siglo $x v$ y parte del siguiente la letra típica de los breves pontificios.

Originariamente, la letra «humanística cancilleresca» es una simplificación de la "gótica" de cancillería italiana gracias al influjo de la "humanistica redonda», que más tarde (siglo XV) se convertirá en una variante de la "humanística cursiva». En opinión de Federici, cuando la "humanística»

65 A. MillaRes, op. cit., vol. I, p. 219. Opina, además, que en los ebreves" papales de las centurias decimoquinta y siguiente alcanzo esta letra su mayor perfeccionamiento.

66 G. CencettI, op. cit., p. 292. 
documentaria italiana alcanza un alto grado de estilización de sus caracteres, mayor regularidad y homogeneidad en su trazado y respetuosa elegancia respecto de las formas más alfabéticas, nos hallamos de lleno ante la "humanística cancilleresca" de las cancillerías de Italia septentrional y de la Curia Pontificia, que poco después pasarán al resto de las cancillerías y curias europeas ${ }^{67}$.

Debido a la inclinación cabeceante hacia la derecha de determinados astiles: $b, d, h, l, y$ también al puntazo o «testa» en que rematan los ápices superiores de algunas de ellas, los paleógrafos italianos la llamaron «testegiata» ${ }^{68}$.

La reforma caligráfica de Luis de Henricis, el Vicentino, en 1522, consistente en separar la caligrafía de los propósitos geometrizantes con que la habían creado a finales del siglo XV y comienzos del siguiente $D$. da Moille y L. Pacioli ${ }^{69}$ y, sobre todo, en dar preferencia a las formas estéticamente más agradables - según el citado prof. Casamassima - se hizo, precisamente, con la expresa intención de difundir la letra cancilleresca ${ }^{70}$.

La abundancia de elementos decorativos en astiles y caídos de algunas "humanísticas cancillerescas» no puede extrapolarse a todas. Tampoco se pueden exagerar — por no ser aplicable a todas - la estilización y marcada inclinación hacia la derecha ${ }^{71}$.

\section{D) Humanística corriente}

Para algunos, se trata de una variante de la «humanística cursiva", aunque trazada con mucha rapidez, de uso frecuente en notas marginales, cartas, escritos personales y en documentos judiciales y administrativos. Como la "cancilleresca" y, tal vez, en mayor grado y medida, la "corriente" admite distintas variedades y grados de cursividad, y en determinaclos modelos de fines del XV y del XVI, parece depender más de la "gótica

67 V. Federicl, Paleografia Latina, Roma, 1935, p. 171.

68 Ver fig. 10. Códice De vita et moribus lulii Agricolae Liber de Cornelio Tácito, escrito en "humanística cursiva cancilleresca" por Julio Pomponio Leto entre 1465-1470 y conservado en la Biblioteca Apostólica Vaticana (Ms. Vat. Lat. 3429).

6y D. Da Mollle, Alphabetum Romanum, Roma, 1480. L. PaClol, Divina Proportione, 1509.

E. Casamassima, Tratati di Scrittura del Cinquocento Italiano, Milán, 1966.

Ver fig. 11. Cédula real de Carlos V, fechada el 4 de septiembre de 1542 en Monzón, dirigida al corregidor de Toledo para que provea que se tomen las sobras del encabezamiento de aquella ciudad para la paga del sueldo de la parte que han ofrecido. Letra «humanística cursiva cancilleresca". Se conserva en el Archivo Municipal de Toledo, "Archivo Secreto", cajón 1. , legajo $2 .^{\circ}$, n. ${ }^{\circ} 55$. 
cursiva" y aún de la "procesal" en grado menor que de la propia "humanística cursiva". De ahí que no falten especialistas que la consideran procedente de la "gótica cursiva cortesana", "procesal", etc., bien con influencias y elementos de la "humanística cursiva" 72.

El prof. Jacques Stiennon no tiene dudas cuando manifiesta que esta «humanística corriente" es, simplemente, una variante de la "gótica cursiva" ${ }^{73}$, si bien otros autores, fijándose en determinados modelos, la llaman "bastarda italiana", para diferenciarla de la "gótica bastarda" francesa del siglo Xiv. Gencetti, por su parte, describe la "bastarda italiana": "como una consecuencia del incipiente gusto barroco surgido en la segunda mitad del siglo $\mathrm{x} v$ si bien el proceso de formación de la escritura bastarda no culmina hasta el siglo siguiente (s. Xvi), caracterizándose por la ligereza y fluidez del trazo; por el fácil uso de las ligaduras, conseguidas mediante amplios perfiles; $y$ por la longitud de sus astas fuertemente curvadas hacia la derecha, si se trata de astiles superiores, y hacia la izquierda, si de los caídos inferiores. No menos llamativos y característicos - añade Cencetti- son sus engrosamientos terminales, arriba y abajo, a modo de gota o voladizo, y sus amplios trazos y rasgos complementarios que sirven para entrelazar determinadas letras o dar paso a espontáneas y prolongadas fugas y rasgueos. En el siglo xvill ("Settecento") pierde estas exuberancias, sufre la influencia francesa y en el xIX ("Ottocento"), la de la cursiva inglesa" ${ }^{74}$.

\section{E) Humanística notarial y mercantil}

Se la distingue con nombres diferentes. En Italia se la llama: «scrittura mercantesca" y "mercantile»; en Francia: «lettre financière»; en Inglaterra: "Chancery Hand", "Court Hand" y "Secretary Hand"; y en Alemania: "Zerstrenung», "Kurrentschrift», "Handelsschrift" y "Kaufmannisch». En España, algunos la llaman, «letra mercantil», «escritura de la administración", "letra de finanzas", etc.

72 Ver fig. 12. Petición autógrafa de Dominico Theotocopuli (El Greco), fechada en Toledo el 8 de mayo de 1587, por la que solicita al corregidor de Toledo que se le abonen los gastos que ha tenido por la realización de los dos arcos en las fiestas celebradas con motivo del traslado de los restos de Santa Leocadia. Letra "humanística corriente" (Archivo Municipal de Toledo, "Festejos", caja 2). Se puede advertir la forma peculiar que adoptan los caídos de ciertas letras, por ejemplo: $p, q, z$, subiendo por su derecha para unirse a la letra siguiente.

73 J. STIENNON, op. cit., p. 120.

74 G. CEnCETT, Compendio di Paleografia Latina, Roma, 1978, p. 87. 
Los modelos humanísticos administrativos, notariales y mercantiles son, sin duda, el mejor exponente de la gran libertad personal e individual alcanzada en la sociedad en cuanto al sistema escriturario ${ }^{75}$. Al igual que los tipos de la "humanística corriente" los de la "notarial y "mercantil" representan y son una variante de la "gótica cursiva". Se caracteriza -dentro de las oficinas y escribanias notariales, y centros administrativos y de comercio- por la agilidad y viveza de formas $y$, especialmente, por la gran flexibilidad y capacidad de adaptarse no sólo a los gustos y tendencias personales de los escribanos de oficio que les permite dar a sus escritos una impronta propia e individual, sino también a muchísimas personas acostumbradas a escribir y resolver sus asuntos y negocios administrativos valiéndose de estas "humanísticas" que, unos denominan "notariales" por considerar a dichos centros y a sus oficiales como los promotores y difusores más valiosos ${ }^{76}$, y otros «mercantiles» por ser la más utilizada por hombres de negocios y personal dedicado a escriturar asuntos de esta naturaleza ${ }^{77}$. Estas "humanísticas» se trazaban con pluma de corte redondo, más o menos largo.

El uso constante de estas grafías en cartas, minutas, compraventas, negocios privados y actos notariales e instrumentos jurídico-administrativos de todo tipo, tanto en Italia como fuera de ella, muestra a todas luces - a través de sus caracteres gráficos tipificados- el constante desarrollo de un sistema práctico que servirá de base y fundamento creativo a las distintas escrituras modernas de Europa y América. Su formación, según expone Orlandelli ${ }^{78}$, se origina a finales del siglo XIII, momento en que se produce un aumento de la actividad artesanal, mercantil, notarial, bancaria, comercial, etc; ofrece una particular manifestación gráfica, sobre todo en el siglo $\mathrm{xV}$, adquiriendo un desarrollo notable en la segunda mitad de esta centuria, período en que adopta un ductus decididamente más cursivo y con ligados más frecuentes, circunstancia que conlleva mayor dificultad

\footnotetext{
75 Pueden consultarse los estudios: G. Costamagna, "Evoluzione della corsiva notarile genovese nei secoli XVI e XVI»", Miscellanea in Memoria G. Cencetti, Turín, 1973, pp. 191-213; y J. MAZZOLENI, L'Atto Notarile Napoletano nei Secoli xv e Xvi, Nápoles, 1968.

76 Ver fig. 13. Ejemplo de letra "humanística corriente", trazada por el notario Juan Palomba en el Libro anual de protocolos correspondiente al año 1525. Se conserva en el A. S. N., Notai, sch. 24, 63 (Nápoles, 1525). Incluye su signo en el ángulo inferior derecho.

77 Ver fig. 14. Fragmento de una póliza de seguro, en “humanística mercantil» de mano del florentino Jacobo Pucci, escrita en Génova el día 4 de febrero de 1394. (Reprod. por F. Melis en su trabajo Documenti per la storia economica dei secoli xil-xiv, Firenze, 1972, lám. 113). Es destacable que el escriba ha adoptado en la datación el estilo de la Encarnación, según el cómputo florentino.

${ }_{78}$ G. ORLANDELLI, “Osservazioni sulla scrittura mercantesca dei secc. XIV-xv", Studi in Onore di Ricardo Filangieri, 1 (1959), pp. 445-460.
} 
de interpretación. Dichas grafías, con caracteres autónomos y distintivos, perduran hasta finales del siguiente siglo, extinguiéndose gradualmente.

En muchos casos estas escrituras "notariales", "mercantiles", "administrativas y de "finanzas" suponen -desde el punto de vista gráfico- un estado intermedio de tránsito o paso hacia la "humanística corriente" más cursiva de los siglos XV y XVI, y no una derivación directa de las "humanísticas», sino de las "góticas cursivas» decadentes e irregulares, próximas a las "prehumanísticas" de tipo documental, caracterizadas por la desigualdad de sus letras y caracteres cursivos minúsculos, como ocurre en algunos diplomas y registros del rey Alfonso $\mathrm{V}$ de Aragón anteriores al año 1442 , si bien en otros privilegios alfonsinos, posteriores a la fecha señalada, presentan una grafía mucho más caligráfica, de letra más redondeada y cuidada, muy próxima a la "humanística cancilleresca" de libros, en cuanto a claridad y regularidad, sin apenas abreviaturas, de trazo vertical (derecho), letras bien proporcionadas y armónicas con ligera y gradual tendencia a cierta cursividad e inclinación hacia la derecha.

\section{BIBLIOGRAFÍA}

Finalmente, paso a la bibliografía, distinguiendo: A) Obras y trabajos de carácter general relativos a los distintos tipos de "escritura humanística»; B) Estudios históricos en relación con el "Humanismo" y el Renacimiento;

C) Obras referentes a los escritores humanistas; y D) Obras de paleografia propiamente dicha.

\section{A) De carácter general:}

Aulotte, R., Bozzolo, C. y Chomarat, J., les humanistes et l'antiquité grecque. Textes rassembles, París, 1989.

Battelli, G., Nomenclature des écritures humanistiques, "l Colloque International de Paléographie Latine», 1954, págs. 35-44.

BILlanovich, G., Alle origini della scrittura umanistica. Padova 1261 e Firenze 1397, "Miscellanea A. Campana», vol. I, Padua, 1981, págs. 125-140.

Bulanovich, G., La tradizione del testo di Livio e le origini dell' Umanesimo, Padua, 1981.

CASAMASSIMA, E., Lettere antiche: Note per la storia della riforma grafica umanistica, "Gutenberg Jahrbuch», 39 (1964), págs. 13-26.

CASAMASSIMA, E., "Litterae gothicae": note per la storia de la riforma gráfica umanistica, "La Bibliofilia", LXII (1960), págs. 109-143.

Casamassima, E., Per una storia delle dottrine paleographiche dall' Umanesimo a Jean Mabillon, "Studi Medievali, V (1964), págs. 525-578.

Derolez, A., Codicologie des manuscrits en écriture humanistique sur parchemin, TurnhoutBrepols, 1984.

DOYLE, A. I. y otros, Manuscript to print: tradition and innovation in the Renaissance book, Durham, 1975. 
Ecrire a la fin du Moyen-Age. Le pouvoir et l'écriture en Espagne et en Italie (1450-1530), "Colloque International, France-Espagne-Italie. Aix-en-Provence, 20-22 de octubre, 1988", Marsella, 1990.

GaSPARRI, F., Enseignements et techniques de l'écriture du Moyen Age à la fin du XvI siécle, "Scrittura e Civiltà", 7 (1983), págs. 201-224.

GASPARRI, F., Note sur l'enseignement de l'écriture aux xve-xvie siécles: á propos d'un nouveau placard du xvie siécle découvert a la Bibliothèque Nationale, "Scrittura e Civiltà", (1978), págs. 245-261.

HESSEL, A., Humanistic script of the fifteenth and sixteenth centuries, Oxford, 1960.

Kraus, H. P., Fifty Mediaeval and Renaissance Manuscripts, New York, 1959.

LA MARE, A. C. de, Humanistic script: the first ten years. "Das Errhältnis der Humanisten zum Buch", Boppard, 1977, págs. 39-110.

MEISS, M., Toward a more comprehensive Renaissance Palaeography, "The Art Bulletin", 42 (1960), págs. 97-112.

MORISON, S., Early humanistic script and the first Roman type, "The Library", XXIV (1944).

OMONT, H., Humanistic script of the fifteenth and sixteenth centuries, Oxford, 1960.

ORLANDELLI, G., “Littera nova» $e$ "Littera antiqua" tra glossatori e umanistici, Bolonia, 1964.

OSLEY, A. S., Luminario. A introduction to the Italian writing books of the 16th and 17 th centuries, Nievkoop, 1972.

OsıEY, A. S., The origins of italic type, "Calligraphy and Paleography. Essays presented to A. Fairbank», (1965), págs. 107-120.

Rizzo, S., Il lessico filológico degli umanisti, Roma, 1973.

Scrittura: biblioteche e stampa a Roma nel quatrocento, "Atti del secondo seminario, 1982", Cittá del Vaticano, 1983.

THомAS, D., What is the origin of the "scrittura umanistica», «Bibliofilia", LIII (1951), págs. 1-10.

ULLMAN, B. L., The origin and development of Humanistic script, Roma, 1960.

WARDROP, J., The script of humanism. Some aspects of humanism script, 1460-1560, Oxtord, 1963.

\section{B) De carácter histórico-cultural:}

Actas de las II y III jornadas de Humanismo y Renacimiento, Jaén, 1996.

ARNOLD, R. F., Cultura del Renacimiento, 3. ed., Barcelona, 1936.

BATLloRI, M., De l'humanisme i del Renaixent, Valencia, 1995.

BatlloRi, M., Humanismo y Renacimiento. Estudios Hispano-Europeos, Barcelona, 1987.

$\mathrm{BEC}, \mathrm{CH}$., Les marchandes écrivains. Affaires et humanisme à Florence, 1375-1474, Paris-La Haya, 1967.

BENÉVOlo, L., Historia de la arquitectura del Renacimiento, 2 vols., Madrid, 1973.

BuSCH, H. y LOHSE, B., El Renacimiento, Madrid, 1966.

Clements, R. J., Pieta poesis: literary and humanistic theory in renaissance, Roma, 1960.

CLEMENTS, R. J., The Peregrine muse: studies in comparative renaissance, North Carolina, 1959.

Colombo, C., Humanismo y Renacimiento, Madrid, 1984.

Creadores del libro: del medievo al renacimiento, Madrid, 1994 (ed. J. M. Fernández Catón).

Chastel, A., L'Europe de le Renaissance, Bruselas, 1963.

Deılumeau, J., La civilizacion del Renacimiento, Barcelona, 1977.

Derolez, A., Le fivre manuscrit de la Renaissance, "El libro antiguo español», SalamancaMadrid, II (1992), págs. 177-192 (eds. M. ${ }^{2}$ L. López-Vidriero y P. M. Cátedra)

Di CAMillo, O., El humanismo castellano del siglo $\times V$, Valencia, 1976.

Dresdeu, J., Humanismo y Renacimiento, Madrid, 1968.

FIoravanti, G., Universitá e cittè. Cultura umanistica e cultura scolastica a Siena nel' 400 , Florencia, 1981.

Gall, M., La vida en el Renacimiento, Valencia, 1970.

García EstébANez, E., El Renacimiento: humanismo y sociedad, Madrid, 1987.

GARÍN, E., La revolución cultural del Renacimiento, Barcelona, 1981.

GiLson, E., Humanisme et Renaissance, Paris, 1986.

GutiéRrez Nieto, J. I., El Renacimiento y los orígenes del mundo moderno, Barcelona, 1975.

Humanismo renacentista y mundo clásico, Madrid, 1992 (ed. J. A. Sánchez Marín y M. López Muñoz). 
Jornadas internacionales sobre Humanismo y Renacimiento, Jaén, 1994.

HALE, J. R., The civilization of Europe in the Renaissance, New York, 1995.

HAY, D., La época del Renacimiento: el amanecer de la Edad Moderna, Barcelona, 1969.

Murray, P., Arquitectura del Renacimiento, Madrid, 1979.

NaUERT, Ch. G., Humanism and the culture of Renaissance Europe, Cambridge, 1995.

PANOFSKY, E., Renacimiento y renacimiento en el arte occidental, Madrid, 1975.

PENROSE, B., Travel and discovery in the Renaissance, 1420-1620, Philadelphia, 1952.

Pérez Samper, M. A., Las claves de la Europa renacentista, 1453-1556, Barcelona, 1991.

PETRUCCI, A., Libri, scrittura e publico nel Rinascimento. Guide storica e critica, Roma-Bari, 1979.

ReEse, G., Music in the Renaissance, New York, 1959.

WOORHARD, W. H., Studies in education in the age of the renaissance. 1400-1600, Cambridge, 1924.

\section{C) Referentes a escritores humanistas:}

AbBondanza, R., Una lettera autografa del Boccaccio nell" Archivio di Stado di Peruggia, "Studio sul Boccaccion, 1 (1963), págs. 5-13.

Billanovich, G., I primi umanisti i la tradizioni dei classici latini, "Discorsi Universitari», 14 (1953), págs. 1-33.

Billanovich, G., Petrarca litterato. I. Lo scrittoio de Petrarca, Roma, 1947.

CAmpana, A., Scritture di umanisti, “Rinascimento», 1 (1950), págs. 227-257.

CAROTI, S. y ZamponI, S., Lo escrittoio di Bartolomeo Fonzio, umanista fiorentino, Milán, 1974.

Casamassima, E., Un autografo petrarchesco: la seconda epistola al Pontifice Urbano $V$ (senili. IX.1) nel codice Riccardiano 972, "Miscellanea in memoria di G. Cencetti", Turín, 1973, págs. 235-256.

DEROLEZ, A., The copyng of printed books for humanistcs bibliophiles in the fiftheenth century, "From script to book", Odense, 1986, págs. 140-160.

Hunt, R. W., A manuscript from the Library of Coluccio Salutati, "Calligraphy and Palaeography. Essays presented to A. Fairbank», London, 1965, págs. 75-79.

LA MARE, A. C. DE, The handwriting of Italian humanisis. I, Oxford, 1973.

LA MARE, A. C. DE, y THOMPSON, D. F. S., Poggio's earliest manuscript?, "ltalia Medioevale e Umanistica", 16 (1973), págs. 179-195.

Maillard, J. F., KecskemetI, J. y Portalier, M., L'Europe des Humanistes (xive-xvile siècles, París, 1995.

Muzzıol!, G., Due nuovi codici autografi di Pomponio Leto, "Italia Medioevale e Umanistica", II (1959), págs. 337 y ss.

PERCOPO, E., Vita de Giovani Pontano, Napoli, 1938.

Petrucci, A., Coluccio Salutati, Roma, 1972.

Petrucci, A., /l protocollo notarile di Coluccio Salutati (1372-1373), Milán, 1963.

Petrucci, A., La scrittura di Francesco Petrarca, Cittá del Vaticano, 1967.

Ross, B., Salutati's defeated candidate for humanistic script, "Scrittura e Civiltà», 5 (1981), págs. 187-198.

SoRIA, A., Los humanistas de la corte de Alfonso el Magnánimo, Granada, 1956.

Ullman, B. L., The humanism of Coluccio Salutati, Padua, 1963.

VATTASSO, M., I codici Petrarcheschi della Biblioteca Vaticana, Roma, 1908.

\section{D) De carácter gráfico y escriturario}

\section{Referentes a Italia}

Balsamo, L., Origini del corsivo nella tipografia italiana del cinquecento, Milán, 1967.

BARONE, N., Notizia della scrittura umanistica nei manoscritti e nei documenti napoletani del XV secolo, "Atti della Real Accademia di Archeologia, Lettere e de Belle Arti», Nápoles, XX (1899), págs. 1-11. 
Casamassima, E., Trattati di scrittura del cinquecento italiano, Milán, 1966.

Costamagna, G., Evoluzione della corsiva notarile genovese nei secoli Xvi e XVII, "Miscellanea in memoria G. Cencetti», Turín, 1973, págs. 191-213.

DEROLEZ, A., Observations on the colophons of the humanistic scribes in fifteenth-century ltaly, «Paläographie, 1981», Munich, 1982, págs. 249-262.

FEDERICI, V., La scrittura delle cancellerie italiane dal sec. xII al xvili, Roma, 1904.

MAZZOLENI, J., Esempi di scritture cancelleresche, curiali e minuscole, Nápoles, 1972.

MAZZOLENI, J., L'atto notarile napoletano nei secoli xv e xvi, Nápoles, 1968.

MoRison, S., Early italian Writing Cooks. Renaissance to Baroque, Londres, 1990.

Orlandell., G., Osservazioni sulla scrittura mercantesca dei secc. XIV-XV, "Studi in onore di Ricardo Filangieri», 1 (1959), págs. 445-460.

PAGNIN, B., Annotazioni sulla “littera antique» del secolo xv, "Medioevo e Rinascimento Veneto. Studi in onore de Lino Lazzarini», I (1979), págs. 283-292.

Petrucci, A., Scrittura, alfabetismo ed educazione grafica nella Roma del primo cinquecento: da un libretto di conti di Maddalena Pizzicarola in Trastevere, "Scrittura e Civiltà", 2 (1978), págs. 163-207.

\section{Relativas a la península lbérica}

Álvarez MÁrquez, C., Escritura latina en la Edad Moderna: la escritura humanística, Sevilla, 1995.

Arago, A. M., Prenotaciones a la escritura cancilleresca de Alfonso el Magnánimo, "IX Congreso de $H_{.}{ }^{\circledR}$ de la Corona de Aragón", II (1977), págs. 49-55.

ARIENZO, L. D', Alcune considerazioni sul passagio della scrittura gotica all' umanistica nella produzione documentaria catalana dei secoli XIV e XV, "Studi di Paleografia e Diplomatica", (1974), págs. 199-226.

BatLloRI, M., La cultura de Sardenya, Sicilia i Nápols al segle XVI en relació amb els estats catalano-aragoneses, "VIII Congreso de H." de la Corona de Aragón", 1973, págs. 37-70.

BARONE, E., Notizia della scrittura umanistica nei manoscritti e nei documenti napoletani del sec. XV, Napoli, 1899.

Gimeno, F. y TRENCHS, J., La escritura medieval en la Corona de Aragón (1137-1500), «lll Curso de Estudios Universitarios Benassal-Castelló: Paleografía".

MANDINGORRA, M. L., La escritura humanística en Valencia: su introducción y difusión en el siglo XV, «Estudis Castellonencs", 3 (1986), págs. 5-94.

MARINIS, T. DE, Biblioteca Napolitana dei Rei d'Aragona, Milán, 1947-1952.

MATEU Y LloPIS, F., La decadencia de la escritura según el testimonio de Luis Vives, "Revista de Filologia Española», XXIX (1945), págs. 97-120.

Rodicio, S., La escritura humanistica y su extensión a Hispanoamérica, Madrid, 1995.

RuBio, J., Humanisme i Renaixement, "VIII Congreso de H. de la Corona de Aragón, 1973, págs. 9-36.

Usón, M., Contribución al estudio de la cultura medieval aragonesa. La escritura de Aragón del siglo $x ı$ al XVII, Zaragoza, 1940.

\section{A nivel europeo}

A.utenrieth, J. (ed.), Renaissance und Humanisten handschriften, Munich, 1988.

BLUNT, W. J. y CARTER, W., Italic handwriting: some examples of everyday cursive hands, Londres, 1954.

FalRBank, A. J. y Dickens, B., The Italic hand in Tudor Cambridge, London, 1962.

FaIRBANK, A. J. y HuNT, R. W., Humanistic script of the fifteenth and sixteenth centuries, Oxford, 1960.

FAIRBANK, A. J. y WOLPE, B., Renaissance handwriting: an anthology of Italic scripts, Londres, 1960.

Fichtenau, H., Die Lehrbucher Maximilians I und die anfange der Frakturschrift, Hamburgo, 1961. 
Frenz, T., Das Eindringen humanistischer Schriftsformen in die Urkunden und Akten der Päpstlichen Kurie im .15. Jahrhundert, "Archiv für Diplomatik», 19 (1973), págs. 287-418 y 20 (1974), págs. 384-506.

MALOV, V. N., Les origines de l'écriture moderne: Paléographie des documents français de la fin du xve au xvime siécle, Moscú, 1975.

MENTZ, G., Handschriften der reformationzeit, Bonn, 1912.

Michaud, H., La grande Chancellerie et les écritures royales au seizième siécle (1515-1589), París, 1967.

OSLEY, A. S., Scribes and sources. Handbook of the Chancery hand in the 16th century, London-Boston, 1980.

OuY, G., Jean de Montreuil et l'introduction de l'écriture humanistique en France au début du xve siècle, "Litterae Textuales", 4 (1976), págs. 53-61.

Poulle, E., Paléographie des écritures cursives en France du xve au xvie siécle, Ginebra, 1966.

Samarán, Ch., Cursives françaises des xve, xvie et xvile siécles, "Journal des Savants", (1967), págs. 129-153.

SPUNAR, P., Die reception der Humanistichen Schrift in Böhman und ihre semiotische Bedentung, «Paläographie, 1981", Munich, 1982, págs. 201-207.

WeIss, R., Humanism in England during the fifteenth century, Oxford, 1967.

WHALLEY, J. I., English handwriting, 1540-1853. An illustration survey, Londres, 1969. 


\section{ILUSTRACIONES}

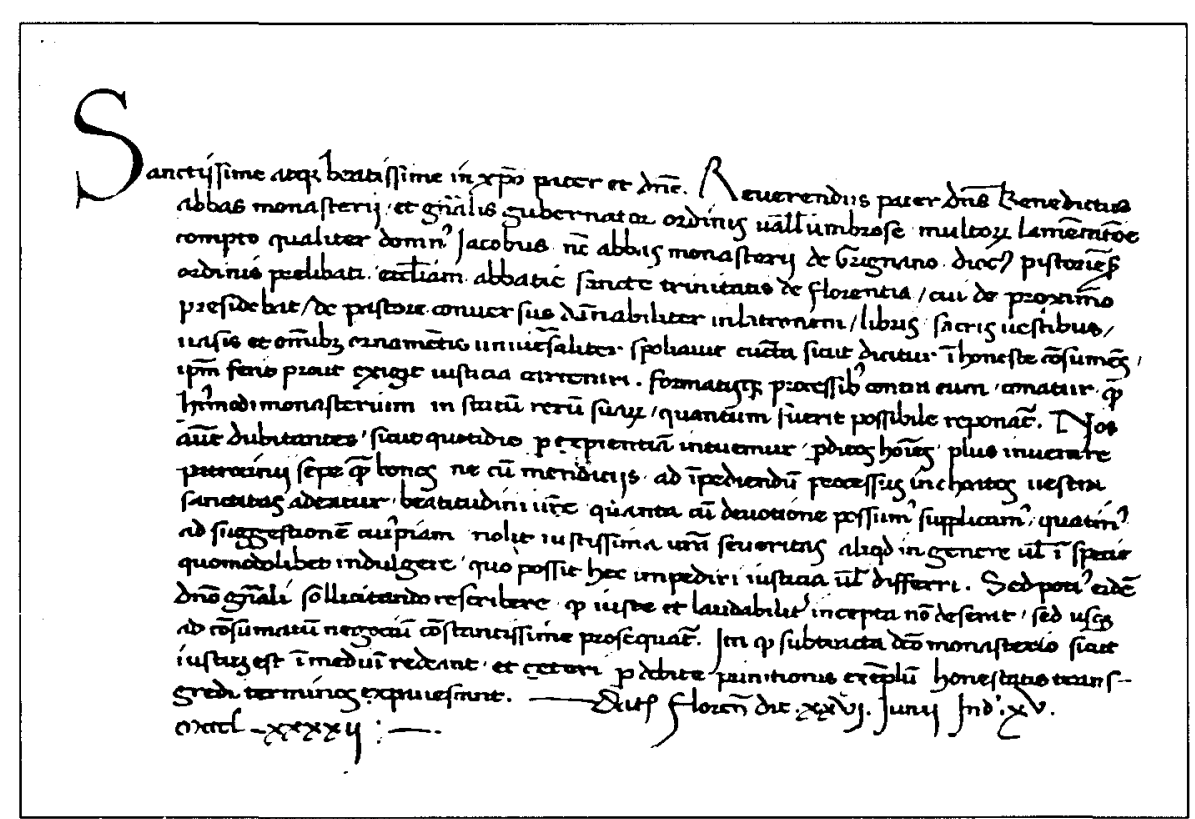

Figura 1

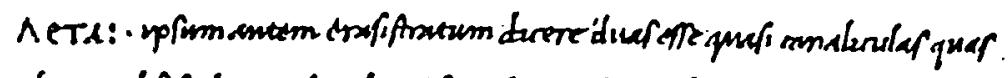

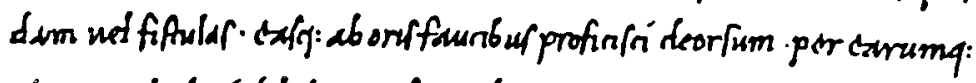

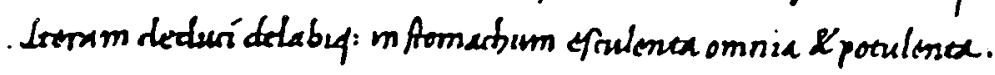

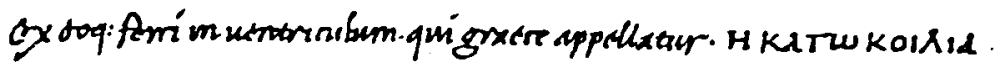

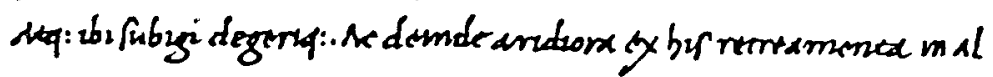

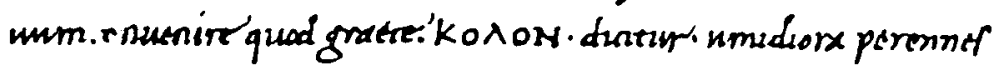

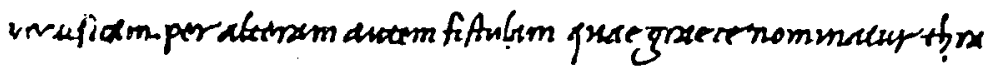


muloy que udenrazazipu die iffir sur har de qubur curant. iuel foundum ilum tzanhan onem. Endxfer quif prouldiubro fenindum hune modum faluser omne quad fumrex mulisu frdum usrupubule quindo sondir natre slicus cory de quibul curar. Cr omnef

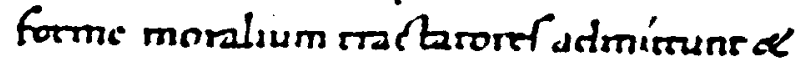

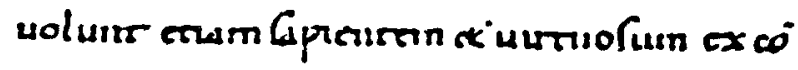
unntor tuipinuduce uerexundum notum

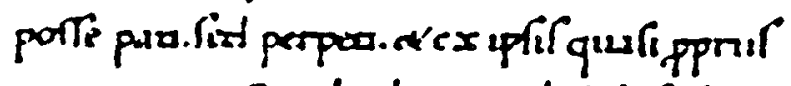
commousz. Quad qdern spued ptrlofoptiusm

Figura 3

C on smmortal belleza eterna fama Ma innanzi atusti da rifar fi uainno. E t quella che plangendo ilmondo ónama C ollamia lingua et colla Ranca penna Ma daebpur duizederla in terra brama. A iriua un fiume che narce ingeberna A mor mide per lei filunga guetra $c$ belamemorra ancora uront acenna. Feluee faxo helbet uifo ferra $c$ he por chara niprero iliuo bet uedo $s$ e fubeato chi Lavide inecria o rdefia adunque aruederla in celo. 
$\therefore$ Gftingto

G)

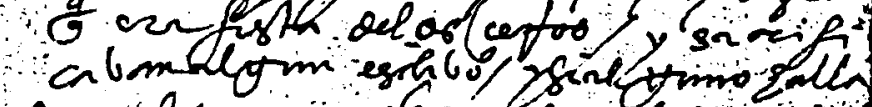

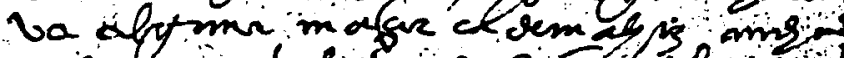

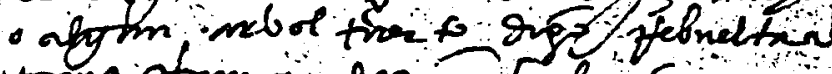

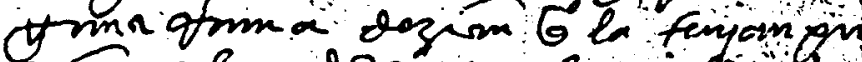

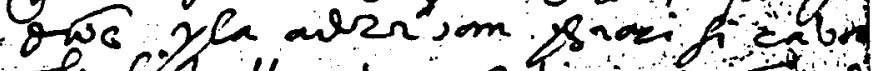

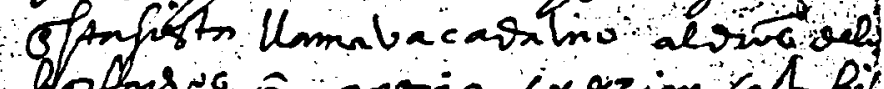

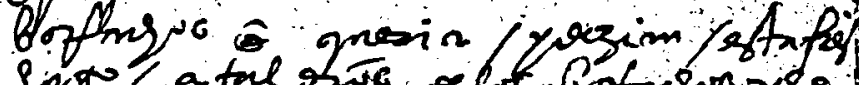
$920 \%$ aitul onte celut Oofrinsoyse covolfing a $6 \mathrm{~m}$ in teberen a opaned

Figura 5

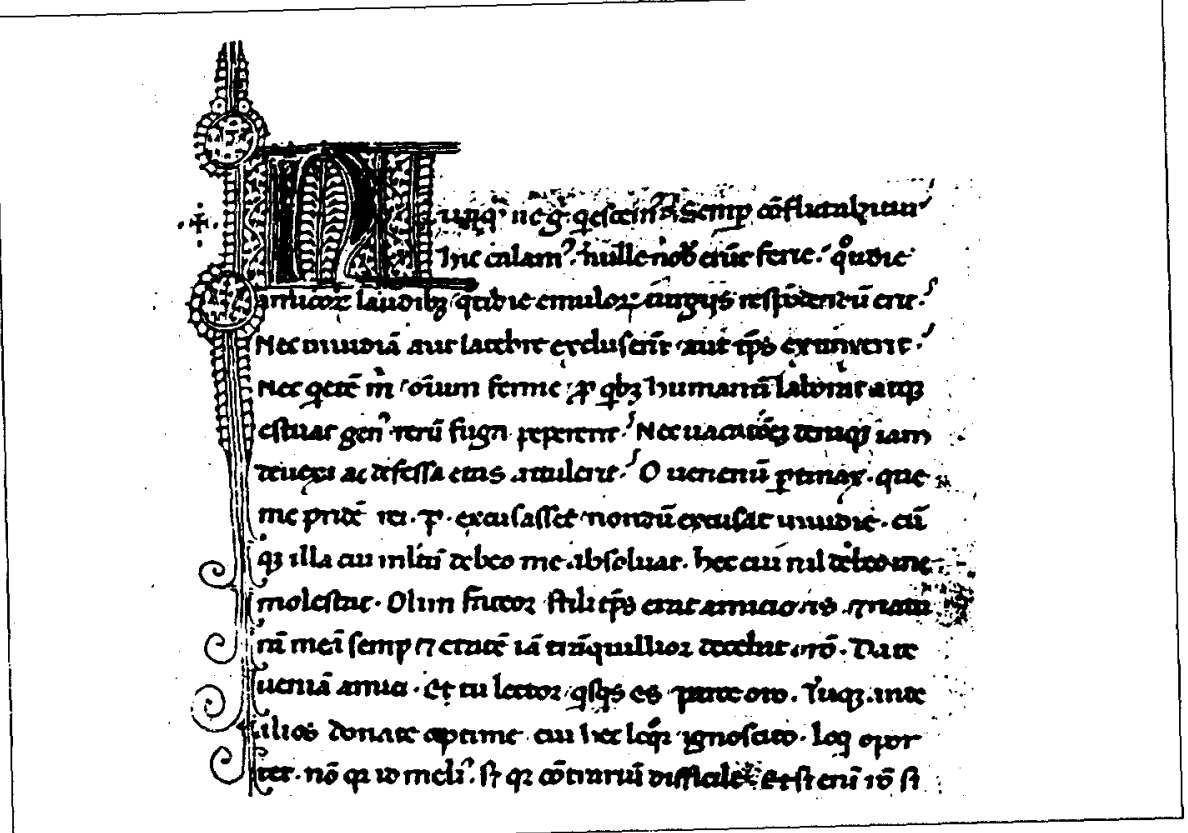

Figura 6 


\section{Soceph}

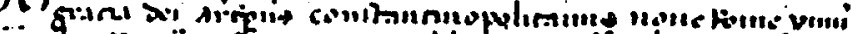

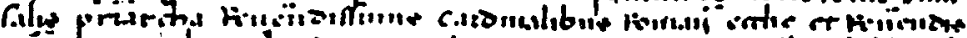

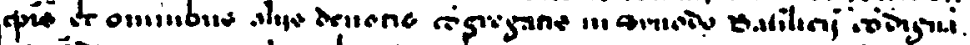

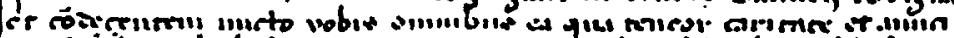

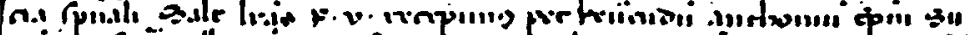

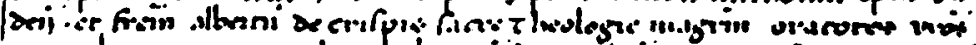

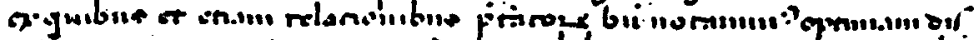

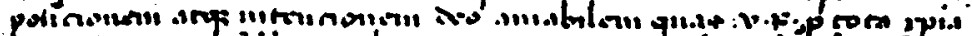

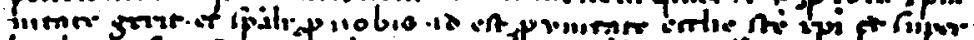

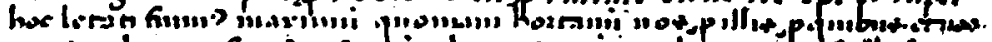

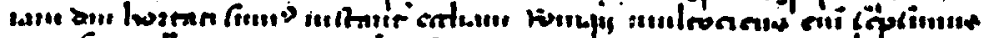

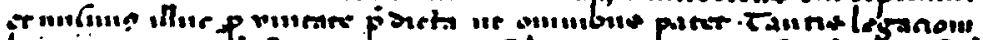

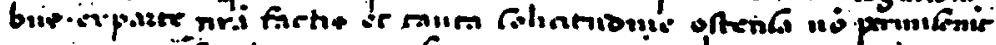

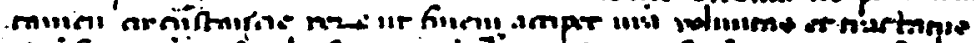

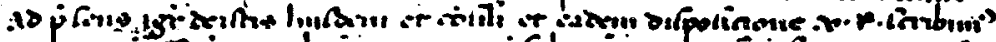

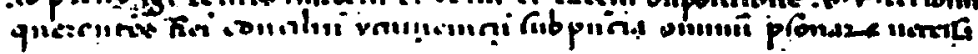

Figura 7

'F ugerar unetro mutabils one raurit.

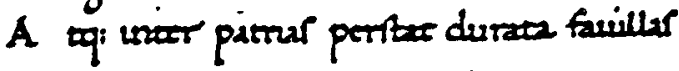

E nubi fyomaum liberaal documenaum

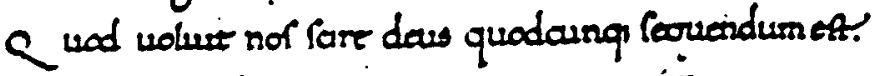

$s$ ub notta ditone fiaum: partung ramifim.

2 Leturam calesre uins: duo cedere urr

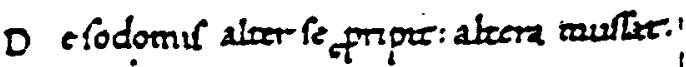

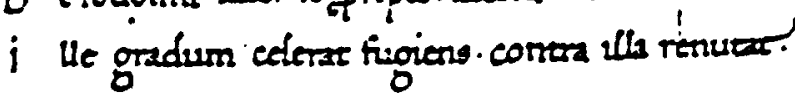




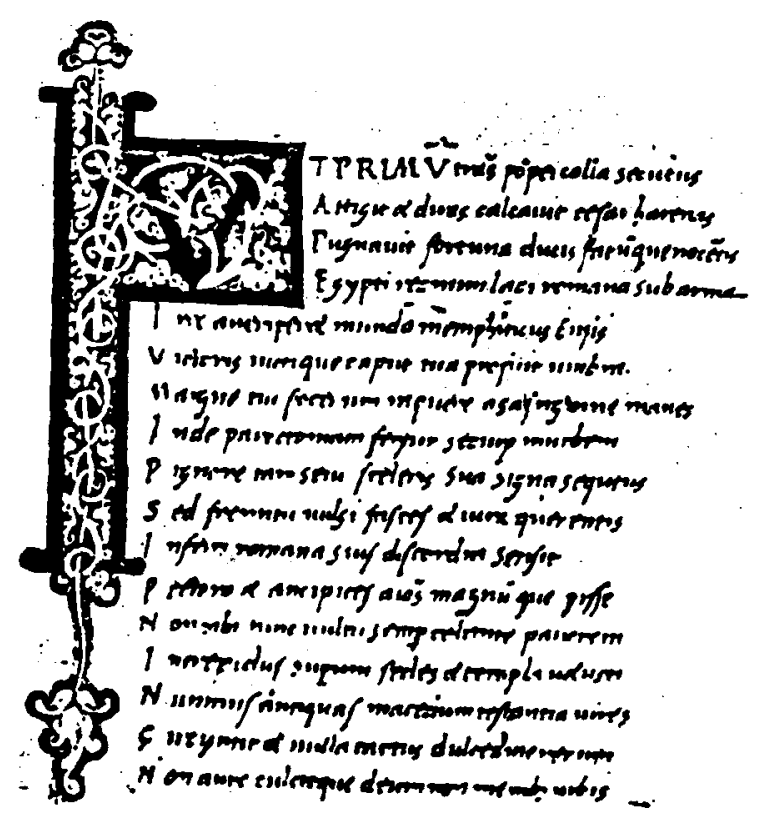

Figura 9

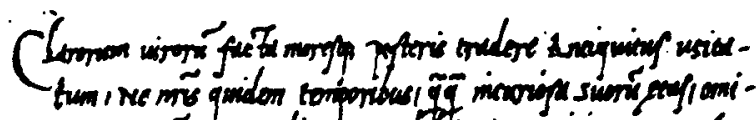

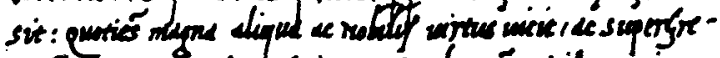

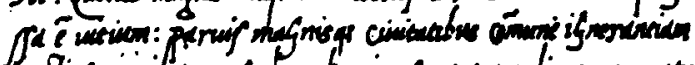

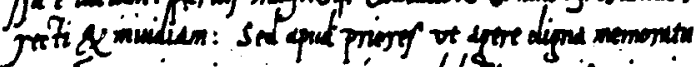

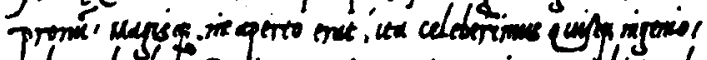

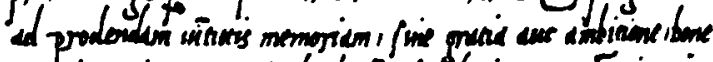

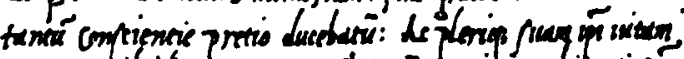

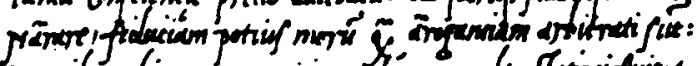

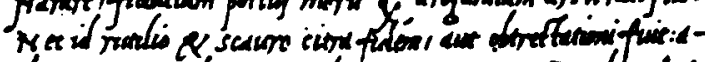

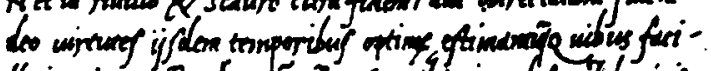

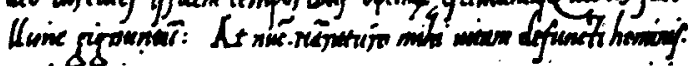




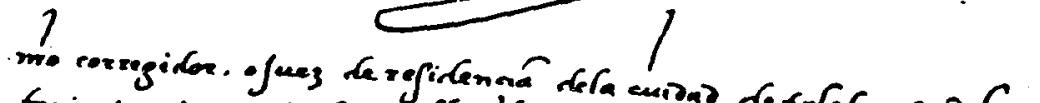

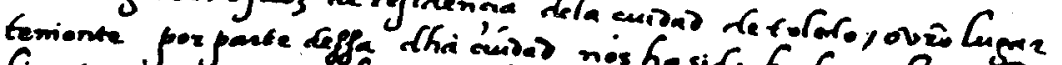

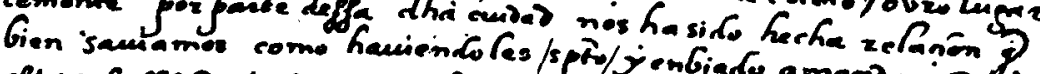

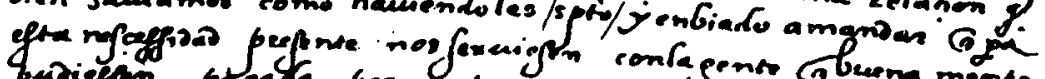

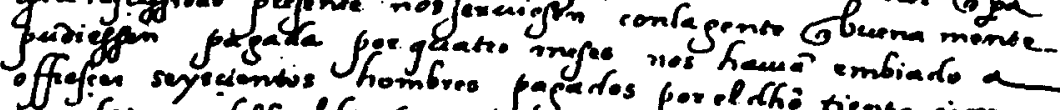

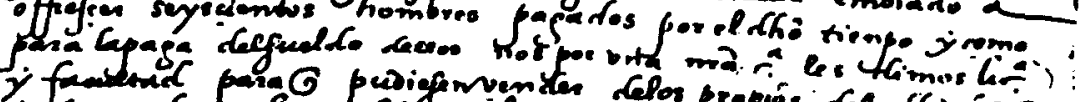

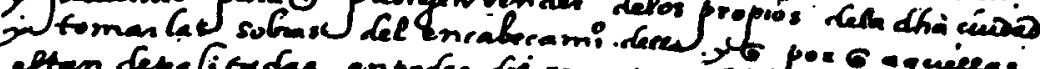

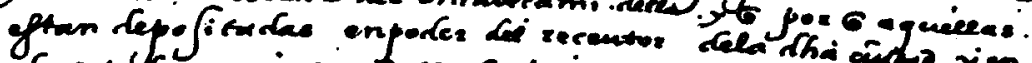

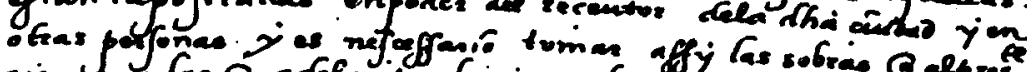

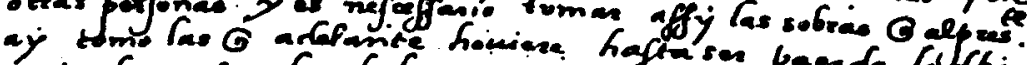

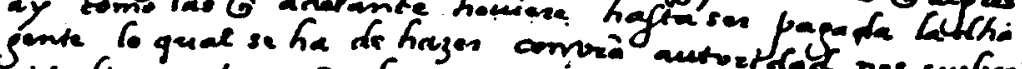

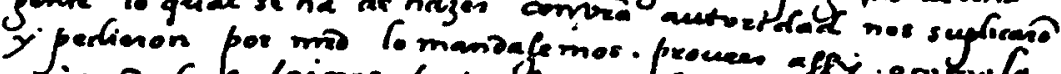

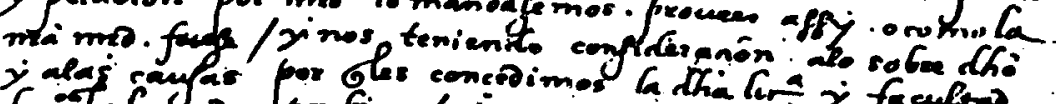

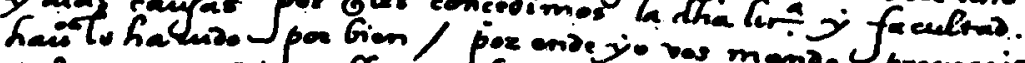

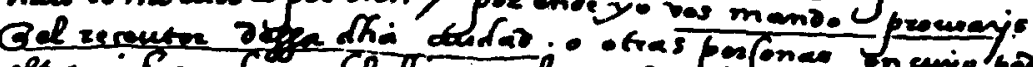

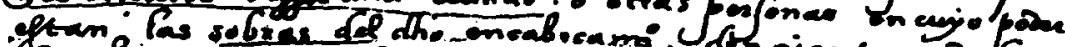

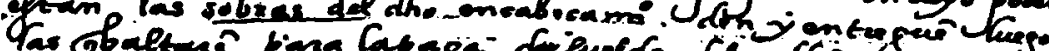

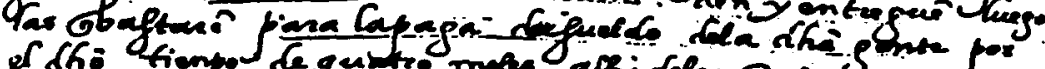

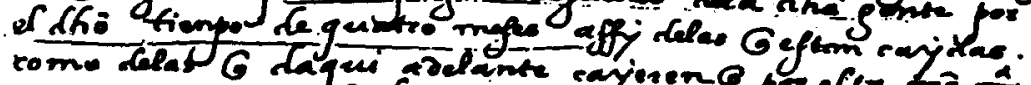

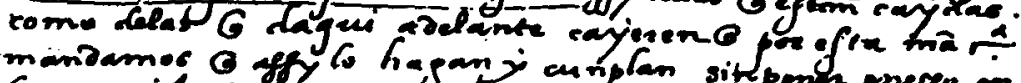

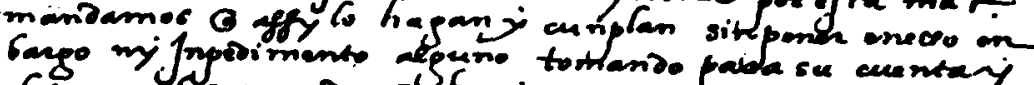

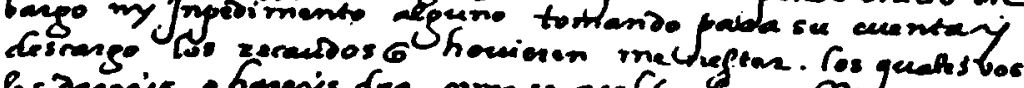

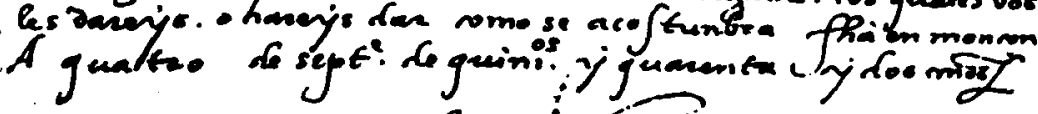

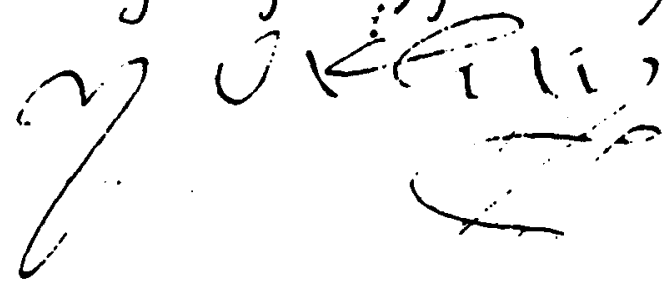




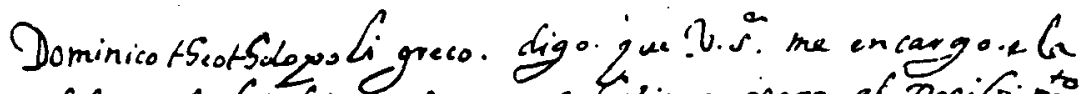

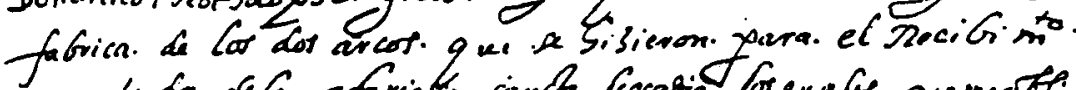

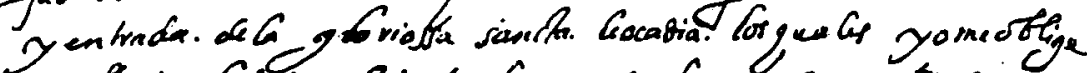

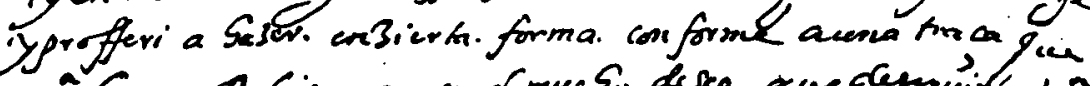

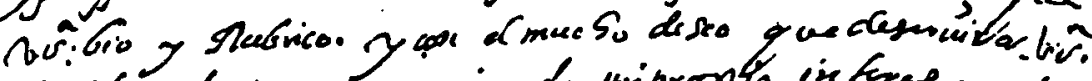

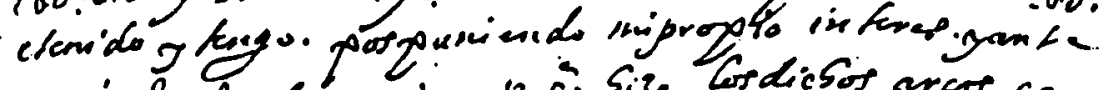

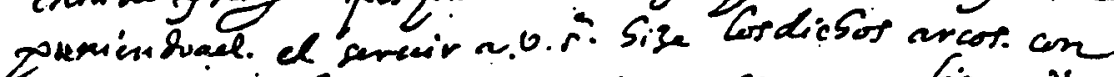

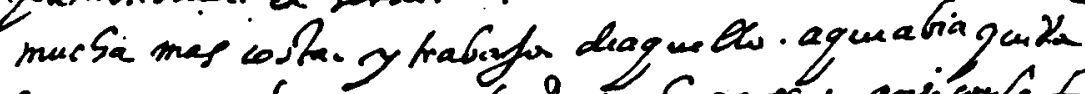

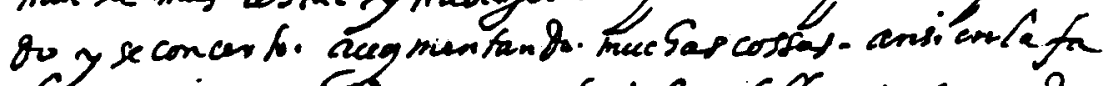

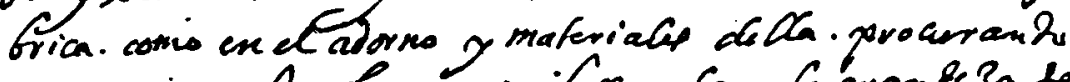

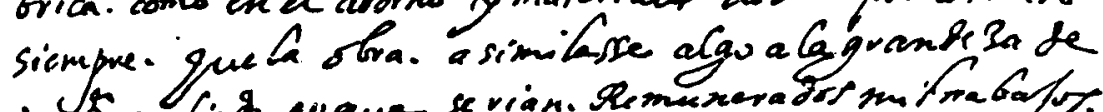

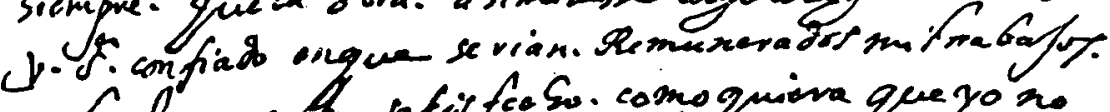

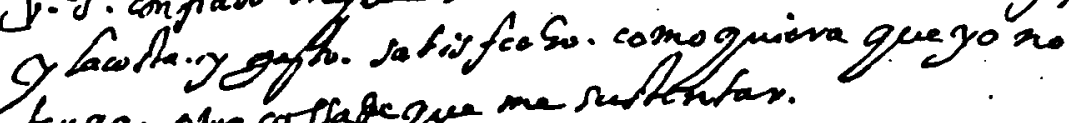
kxga. orra costadeque me surtthtas.

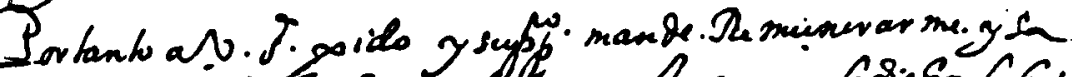

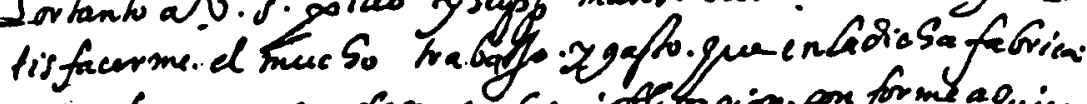

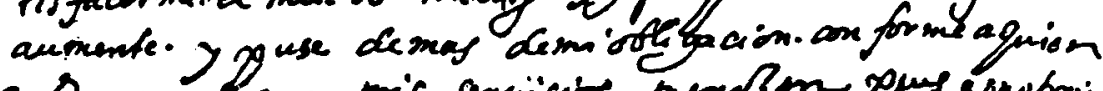

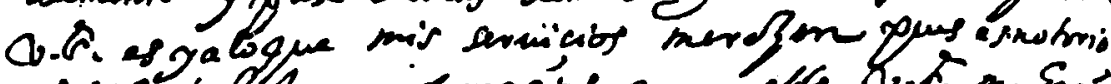

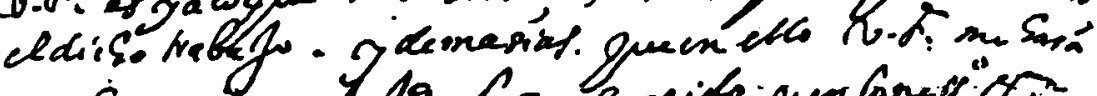

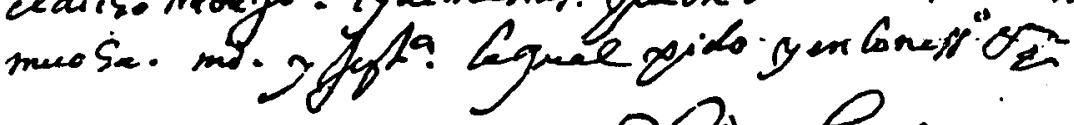

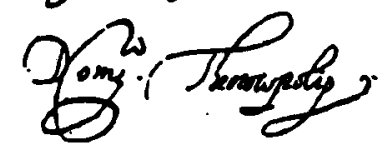

Figura 12 


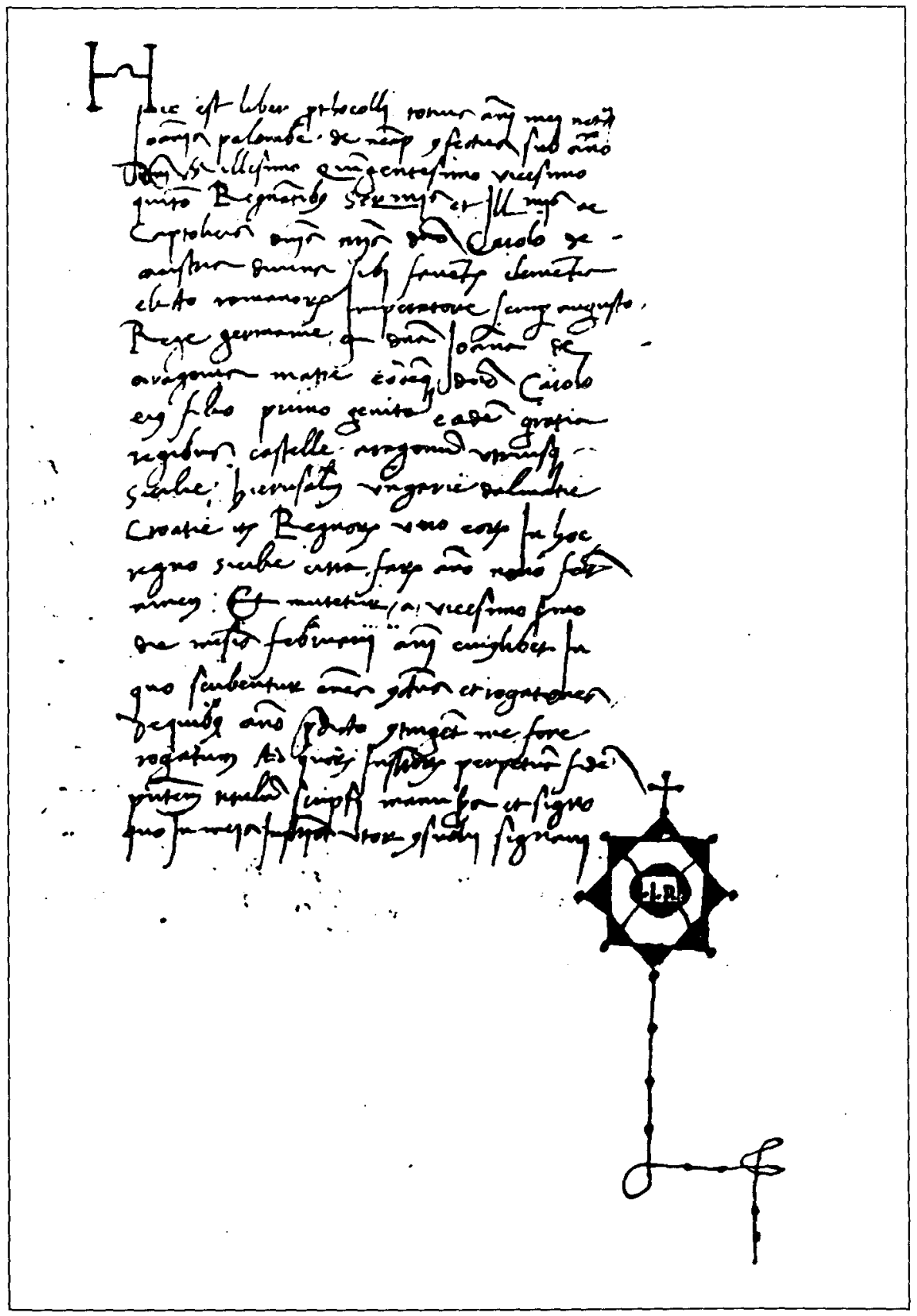

Figura 13 


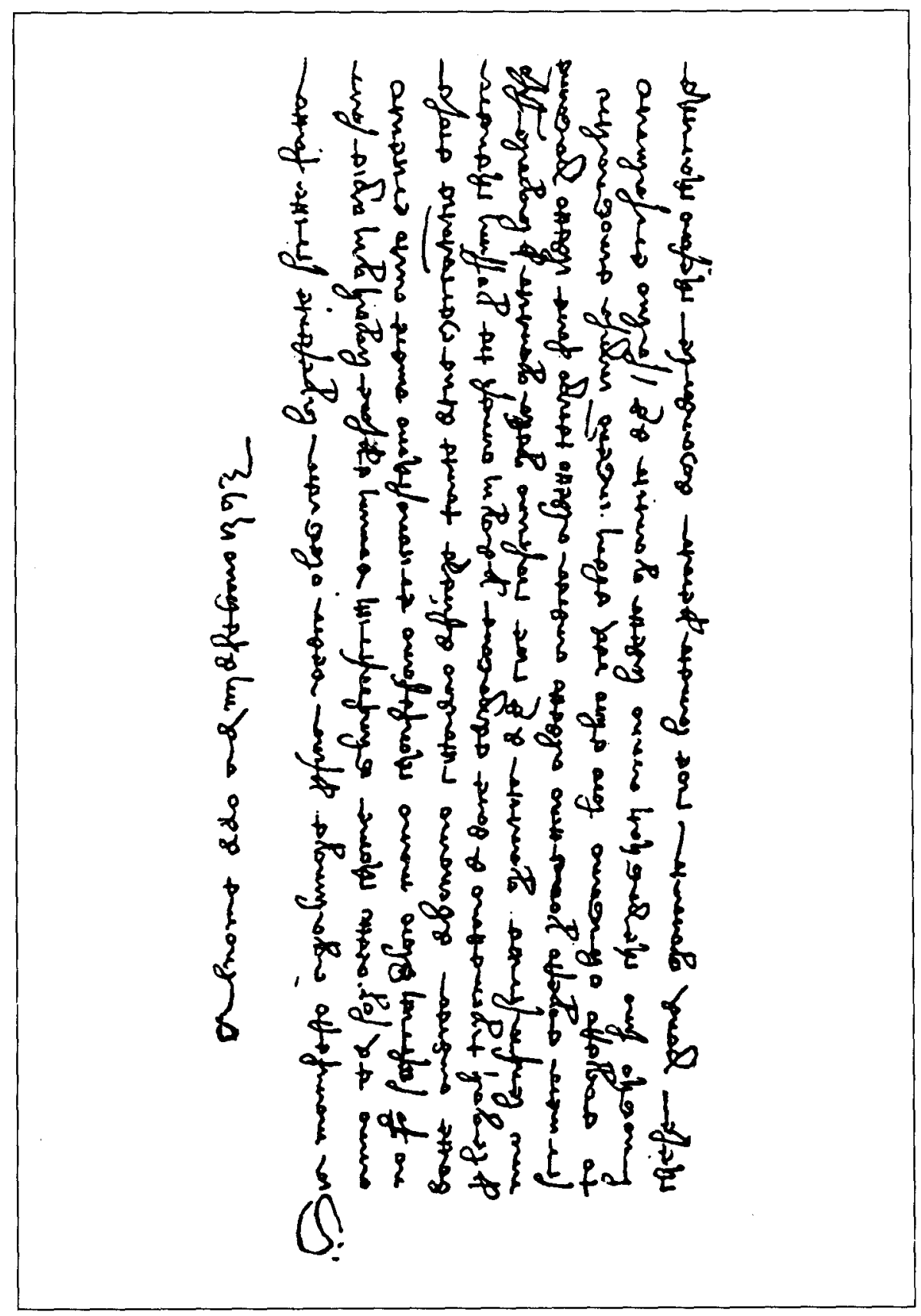

Figura 14 